Florida International University FIU Digital Commons

$3-3-2015$

\title{
The Effectiveness of an Online Workshop on Behavior Management as a Professional Development Tool for Teachers
}

Aparajita B. Kuriyan

Florida International University, abisw001@fiu.edu

DOI: $10.25148 /$ etd.FI15032152

Follow this and additional works at: https:// digitalcommons.fiu.edu/etd

Part of the Child Psychology Commons, Clinical Psychology Commons, School Psychology Commons, and the Teacher Education and Professional Development Commons

\section{Recommended Citation}

Kuriyan, Aparajita B., "The Effectiveness of an Online Workshop on Behavior Management as a Professional Development Tool for Teachers" (2015). FIU Electronic Theses and Dissertations. 1843.

https://digitalcommons.fiu.edu/etd/1843 


\title{
FLORIDA INTERNATIONAL UNIVERSITY \\ Miami, Florida
}

\section{THE EFFECTIVENESS OF AN ONLINE WORKSHOP ON BEHAVIOR}

MANAGEMENT AS A PROFESSIONAL DEVELOPMENT TOOL FOR TEACHERS

\author{
A dissertation submitted in partial fulfillment of \\ the requirements for the degree of \\ DOCTOR OF PHILOSOPHY \\ in \\ PSYCHOLOGY \\ by \\ Aparajita Biswas Kuriyan
}

2015 
To: Dean Michael R. Heithaus

College of Arts and Sciences

This dissertation, written by Aparajita Biswas Kuriyan, and entitled The Effectiveness of an Online Workshop on Behavior Management as a Professional Development Tool for Teachers, having been approved in respect to style and intellectual content, is referred to you for judgment.

I have read this dissertation and recommend that it be approved.

$\begin{array}{r}\hline \text { Stacy Frazier } \\ \hline \text { Daniel Waschbusch } \\ \hline \text { Maureen Kenny } \\ \hline \text { William E. Pelham Jr., Major Professor }\end{array}$

Date of Defense: March 3, 2015

The dissertation of Aparajita Biswas Kuriyan is approved.

\begin{tabular}{r}
\hline $\begin{array}{r}\text { Dean Michael R. Heithaus } \\
\text { College of Arts and Sciences }\end{array}$ \\
\hline Dean Lakshmi N. Reddi \\
University Graduate School
\end{tabular}

Florida International University, 2015 


\section{DEDICATION}

I wish to thank my parents, Prabir and Susmita Biswas, my sister, Indira Biswas and my husband, Ajay Kuriyan for their love, support, and patience throughout the years. 


\section{ACKNOWLEDGMENTS}

I would like to thank my Major Professor, William E. Pelham Jr., for all of the wonderful and unique learning opportunities throughout my graduate career. I am also grateful for Daniel Waschbusch's excellent feedback, which has helped guide my writing throughout the years. I also wish to thank my committee members, Stacy Frazier and Maureen Kenny for their feedback and support of my dissertation. Lastly, I wish to thank the American Psychological Foundation for providing funding to support my dissertation. 


\begin{abstract}
OF THE DISSERTATION
THE EFFECTIVENESS OF AN ONLINE WORKSHOP ON BEHAVIOR MANAGEMENT AS A PROFESSIONAL DEVELOPMENT TOOL FOR TEACHERS

by
\end{abstract}

Aparajita Biswas Kuriyan

Florida International University, 2015

Miami, Florida

Professor William E. Pelham, Jr., Major Professor

The current study examines the effects of an online workshop pertaining to classroom behavior management on teacher self-efficacy, attitudes, motivation, knowledge, and practices. In addition, information about teacher utilization of the Internet, their opinions about professional development, and experiences with classroom management were collected. Participants included $571^{\text {st }}$ through $5^{\text {th }}$ grade special and regular education teachers. Eligible teachers were those who teach an academic subject and had at least one child in the classroom they considered as disruptive. Teachers were randomized to either a training or waitlist group. Classroom observations of teacher practices and questionnaires were utilized. Teachers in the training group participated in two assessment points, baseline and post-workshop, and received access to the online course immediately following the baseline assessment. Teachers in the waitlist group participated in three assessment points, baseline, post-workshop, and follow-up, and received access to the online course immediately following the post-workshop assessment. Findings show that all teachers had access to the Internet at home and at school and used it on a daily basis. The majority of teachers indicated having some past 
training on all the techniques that were presented in the online workshop. All teachers expressed satisfaction with the workshop, indicating that it should be offered again. Postworkshop, findings showed significant group differences in knowledge with a large effect for the training group scoring higher than the waitlist group on a quiz. Secondly, group differences in self-efficacy, knowledge, and attitudes with teachers' past-training as a moderator, was examined. Past-training was not found to be a significant moderator of self-efficacy, knowledge, or attitudes. However, the main effect for training group was significant for attitudes. In addition, teacher attitudes, but not knowledge and selfefficacy, significantly predicted motivation to implement. Next, the moderating effect of barriers on motivation and classroom management skill implementation was examined. Barriers were not found to be a significant moderator. Lastly, the training group was observed to be significantly more effective at giving commands compared to the waitlist group. The current study demonstrates the potential of a low-intensity online workshop on classroom management to enhance the accessibility of teacher professional development. 


\section{TABLE OF CONTENTS}

CHAPTER

PAGE

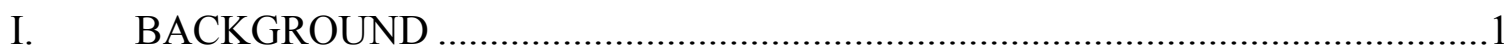

Impact of Ineffective Classroom Management .........................................

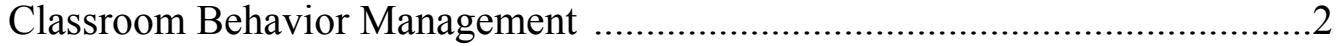

Teacher Professional Development ................................................................ 3

Online Professional Development ...............................................................6

Theoretical Model of Teacher Change ...........................................................9

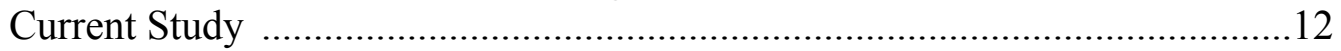

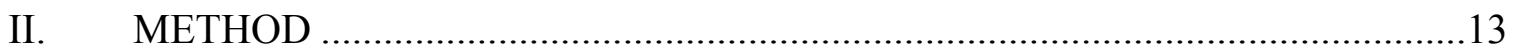

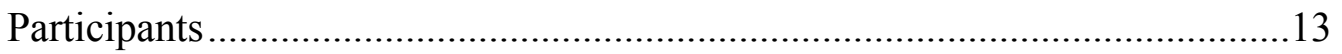

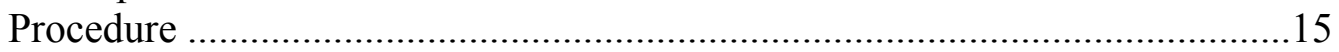

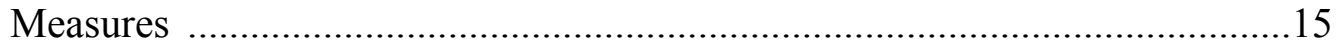

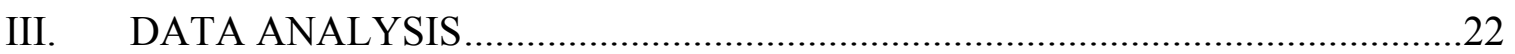

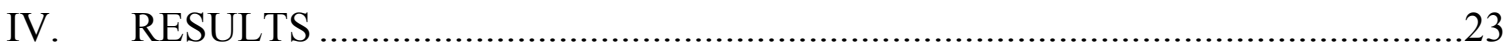

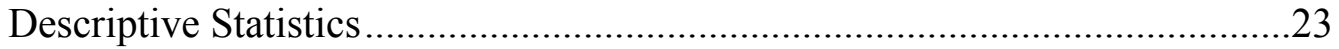

Hypothesized Predictors of Behavior Change ...............................................225

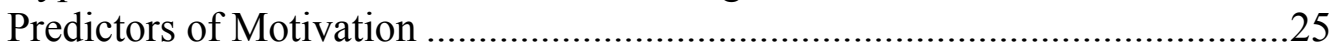

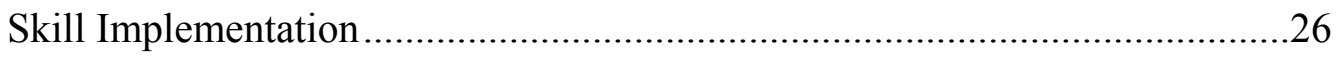

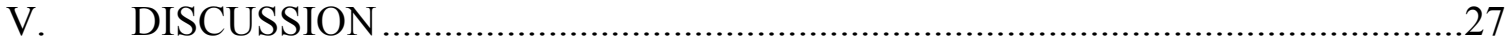

Teacher's Experiences with the Internet ....................................................27

Classroom Behavior Management Techniques: Training and Use...................28

Precursors of Behavior Change ..................................................................30

Motivation and Classroom Management Skill Implementation ....................31

The Effects of an Online Workshop on Teacher Skills ...............................32

Overall Theoretical Model .........................................................................33

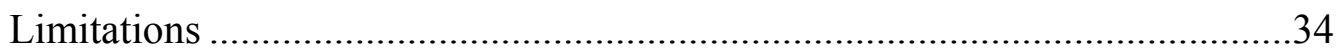

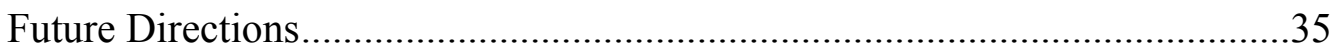

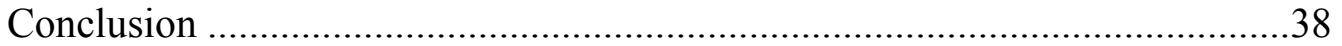

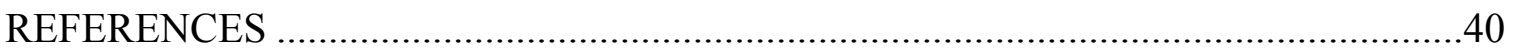

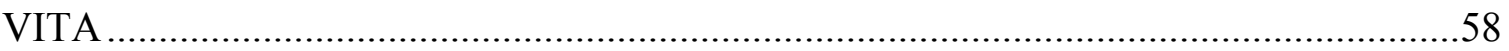




\section{LIST OF TABLES}

TABLE

PAGE

1. Participant Demographics

2. Assessment Schedule

3. Past Training in Techniques Listed from Most to Least Endorsed...............................52

4. Teacher's Past Professional Development on Classroom Behavior Management .......53

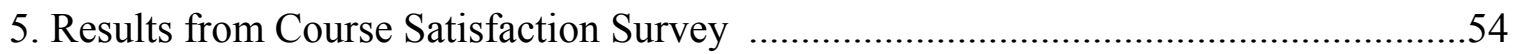

6. ANCOVA Examining the Effect of Motivation on Skill Implementation ...................55

7. Group Differences on Observed Skill Implementation.. .......................................56

8. Negative Binomial Regression Results for Post-Training Group Differences on Percentage Variables. 


\section{ABBREVIATIONS AND ACRONYMS}

ADHD Attention-deficit/hyperactivity disorder

ANCOVA Analysis of covariance

CBTAS Computer Based Training Attitudes Scale

CMT Classroom management techniques

SBTR Student Behavior Teacher Response

TCU The Texas Christian University Workshop Assessment at Follow-up

TSES Teacher Sense of Efficacy Scale 


\section{BACKGROUND}

Ongoing professional development is an inherent part of a teacher's career, the purpose of which is to facilitate the learning of new skills or knowledge in order to improve current practices. School districts spend a substantial amount of funds on professional development programs for school staff (Miles, Odden, Femaanich, Archibald, \& Gallagher, 2004), but these programs are rarely evaluated for their acceptability or their effectiveness (Dede, Ketelhut, Whitehouse, Breit, \& McCloskey, 2009). Although the majority of teachers feel the need for additional training in classroom management and managing children with challenging behavior (Reinke, Stormont, Herman, Puri, \& Goel, 2011), , high-quality professional development activities on this topic are not readily available in all school districts (Wei, DarlingHammond, Andree, Richardson, \& Orphanos, 2009). The purpose of the current study was to evaluate an online professional development workshop on evidence-based practices pertaining to classroom behavior management with respect to changes in teacher self-efficacy, attitudes, motivation, knowledge, and practices.

\section{Impact of Ineffective Classroom Management}

Ineffective classroom management has a negative impact on both teachers and students in the classroom (Shernoff, Mehta, Atkins, Torf, \& Spencer, 2011; Nelson, Maculan, Roberts, \& Ohlund, 2001; Westling, 2010). According to teacher perceptions, about one quarter of students in general education classrooms demonstrate challenging behavior, with much higher rates in special education settings (Westling, 2010). Furthermore, a national survey demonstrated that $33 \%$ of elementary school teachers felt that student misbehavior interfered with their teaching (Robers, Zhang, \& Truman, 2012). 
Considering that disruptive behavior problems are commonly reported in both general and special education classrooms, all teachers could benefit from classroom management skills (Harrison, Vannest, Davis, \& Reynolds, 2012; Westling, 2010). Research has shown that teachers who were not able to manage behavior in their classroom reported lower self-efficacy in their profession (Brouwers \& Tomic, 2000). Furthermore, classroom behavior problems are also inextricably linked to student achievement because of its relationship to time spent on learning tasks. In classrooms where behavior management is poor, students are less frequently engaged in academic tasks (Oliver et al., 2011; Ratcliff et al., 2010). On the other hand, research has shown that effective behavior management in school settings can lead to improved academic achievement, higher levels of student engagement, and more cooperative student behavior (Emmer \& Stough, 2001; Sutherland, Lewis-Palmer, Stichter, \& Morgan, 2008). Even in the absence of overt behavior problems, effective classroom management can prevent the occurrence of future problems.

\section{Classroom Behavior Management}

Currently, many school districts use a response-to intervention framework to identify children at risk for learning disability or school failure (Vujnovic, et al., 2014). Response to intervention is a method for identifying at-risk children that utilizes the child's response to academic interventions using standardized assessments (Fuchs \& Fuchs, 2006). Typically, interventions are presented to the child sequentially from least to most intensive (Fuchs \& Fuchs, 2006). In a response to intervention model, classroom management strategies are evaluated as the first tier of intervention, highlighting the importance of adequate teacher implementation of classroom management strategies 
(Vujnovic, et al., 2014). Unfortunately, many teachers do not receive adequate instruction on classroom management during pre-service preparation programs. A recent review of syllabi from teacher preparation programs in a Mid-western state found that only $27 \%$ of universities had a full course on classroom management (Oliver \& Reschley, 2010). Even with preservice courses on classroom behavior management, teachers reported feeling unprepared to handle disruptive and noncompliant behavior (O'Neill \& Stephenson, 2012; Reinke, Stormont, Herman, Puri, \& Goel, 2011; Westling, 2010). In addition, a recent study demonstrated that both special education and general education teachers were not always able to apply response-to-intervention procedures appropriately and were unable to accurately interpret graphs to make decisions about appropriate interventions for particular students (Vujnovic, et al., 2014). In light of these findings, it is no surprise that teachers feel the need for more training in classroom behavior management (Reinke et al, 2011). Instruction in effective classroom behavior management is relevant for teachers at all stages because teachers may need to adapt behavior management practices as students and classroom dynamics vary every year.

\section{Teacher Professional Development}

As developing proficiency in multiple classroom management strategies is likely not solely developed during preservice training, teachers should be provided with resources and instruction on a variety of evidence-based practices in classroom management to flexibly adapt to their current school environment and students. Professional development is one mechanism by which teachers could receive training about classroom management. The most common format of professional development activities is workshops, conferences, or trainings, and the majority of schools provide 
teachers with scheduled time during the contract year for these activities (Choy, Chen, \& Bugarin, 2006). However, these types of in-person, in-service activities may limit teachers' learning activities to what is readily available at their school district. A national survey on elementary and secondary schools reports that the content of professional development activities is decided by school district staff and principals rather than teachers, and only $11 \%$ of public elementary school teachers felt that they had a great deal of influence in determining the content of in-service activities (Choy et al., 2006). Because in-service activities occur at specific, scheduled times that are not determined by the teacher, they may be unrelated to what teachers need at that moment. Limited input regarding the topic or timing of training may be a reason why in-service programs tend to result in limited changes in the classroom. For example, a randomized controlled trial of an in-service program on ADHD found small effects for special education teachers, but not general education teachers, on self-reported use of behavior modification strategies after the program (Jones \& Chronis-Tuscano, 2008). Nationally, 59\% of public school teachers spent zero hours of professional development time on student discipline and classroom management in a school year (Choy et al., 2006). Westling (2010) surveyed teachers and found that most felt that their in-service and pre-service training on dealing with challenging behavior in the classroom was inadequate. In addition, teachers reported that they learned how to manage challenging behaviors through experience, although very few listed using evidence-based strategies (Westling, 2010). Efforts to increase the availability, accessibility, and palatability of professional development activities on classroom management are therefore needed. 
More intensive, research based, in-person behavior management training programs for teachers have demonstrated positive effects on both teacher and student behavior (Evertson \& Smithey, 2000; Oliver, Wehby, \& Reschly, 2011; Rose \& Church, 1998). Research on professional development for teachers is typically single-subject design or quasi-experimental, and the length and intensity of these training programs vary from one-time in-service trainings to two years of training (Oliver et al., 2011). Although the research-based intensive training efforts have, on average, been successful at improving teachers' behavior management strategies, these types of programs require many resources and are not widely available. For example, one of the most consistent methods of improving classroom behavior management is performance feedback, often provided in the form of coaching or consultation (Duncan, Dufrene, Sterling, \& Tingstrom 2013; Noell et al., 2005; Reinke et al., 2014; Rose \& Church, 1998; Stormont, Reinke, Newcomer, Marchese \& Lewis, 2014). Performance feedback involves monitoring the teacher's behaviors and providing feedback about the behaviors (Noell et al., 2005). Although an effective method for improving teacher performance in the classroom, it is also resource heavy in that it requires an individual to become trained in observational techniques, observe teachers, and provide feedback. In addition, the significant investment of personnel and financial resources to provide performance feedback do not necessarily lead to positive effects for all teachers, maintenance of effects, or even generalization (Becker, 2013; Rice, 2003; Stormont et al., 2014). On average, school districts report being able to conduct classroom observations once per year, per teacher, which is insufficient for reliable and effective feedback (Daley \& Kim, 2010). Consequently, there are many barriers to providing the ideal level of supervision 
and support for teachers' professional development and alternative methods of training must be considered.

Undoubtedly some teachers will require more intensive training for behavior change. However, because of a paucity of resources available for intensive trainings, it may be worth exploring the utility of brief self-administered trainings for professional development. Brief, self-administered trainings have shown some benefits in the teacher professional development literature (Slider, Noell, \& Williams, 2006). Using a multiplebaseline design, Slider, Noell, and Williams (2006) found that teachers who participated in a self-study training, which included video tapes and printed material, improved on the skills presented in the videotapes. Although the study included a small sample size, this is preliminary evidence that for certain teachers, low-intensity interventions may be sufficient to produce behavior change. Considering the cost-effectiveness and potential accessibility of brief, self-administered interventions, more research in this area is warranted to understand who, under what conditions, and for which topics, low-intensity trainings may be useful. Furthermore, online formats may be particularly useful for brief or low-intensity trainings.

\section{Online Professional Development}

Although research on online professional education is incipient, some benefits to online training have been demonstrated. In a recent meta-analysis conducted by the U.S. Department of Education, online learning conditions were found to be more effective than or just as effective as face-to-face experiences (Means, Toyama, Murphy, Bakia, \& Jones, 2010). In fact, a review of online teacher professional development for specific subject material or general pedagogy found that online courses can result in increased 
teacher effectiveness, however, many of these studies do not use randomized designs, nor do they address classroom management courses (Dede et al., 2009). Furthermore, online trainings can encompass a wide variety of training experiences from brief trainings to lengthier workshops with interactive components (Dede et al., 2009). Therefore, variations in online trainings may also impact their effectiveness.

Currently, there are two randomized controlled trials of online professional development trainings for teachers. In the first study, English teachers were randomized to an online professional development training or a control group; Masters and colleagues (2010) found significant and positive effects for the online condition on self-reported instructional practices and knowledge. A more recent randomized study examining a self-paced online professional development course versus an in-person training found no differences in teacher or student outcomes between the two conditions (Fishman et al., 2013). Fishman and colleagues (2013) found that even though the two training conditions were equal, there was a wide variability in time spent utilizing the online training course. Fishman and colleagues (2013) concluded that the self-paced aspect of the online training may have been a way for teachers to customize their training experience because teachers spent only as much time on the course as they needed. Both of the studies reviewed utilized online training programs that were fairly lengthy (e.g. 48 hours and over 100 hours) and focused on content instruction (Fishman et al., 2013; Masters, DeKramer, O’Dwyer, Dash, \& Russell, 2010). Therefore, little is known about brief online trainings for teachers on the topic of classroom management.

Pianta and colleagues (2008) conducted one of the only randomized controlled trials of an Internet-based professional development course involving classroom 
management and observations as the outcome measure. Teachers in the study were in pre-kindergarten classrooms that targeted at-risk preschoolers. The programs to be implemented by the teachers included an evidence-based social-emotional curriculum and language and literacy lesson plans (Pianta et al., 2008). In the study, the lowintensity condition consisted of a web page to which teachers had access, but were not required, to use the online curriculum and one-two minute video examples of behavior management strategies (Whitaker, Kinzie, Kraft-Sayre, Mashburn, \& Pianta, 2007). Overall, the authors found stronger effects for the full intervention compared to the lowintensity condition (Pianta et al., 2008). However, they had some findings that demonstrated some success for the low-intensity training for certain teachers. The authors found a moderating effect for the amount of time spent on the website so that teachers in this low-intensity condition who viewed the website more often demonstrated positive changes in behavior (Pianta et al., 2008). They also found that teachers in the lowintensity condition implemented strategies more frequently than the control group (Whitaker et al., 2007). Pianta and colleagues (2008) also found that teachers in the lowintensity condition who were in moderate poverty classrooms improved just as much as teachers who received the full intervention on three out of the seven domains of the observational system, but teachers in high poverty classrooms did not improve in the lowintensity condition. Therefore, it is possible that certain teachers in certain environments may be able to derive some benefit from low-intensity online interventions.

Research reviewed above clearly demonstrates that it is challenging for most school districts to provide high-intensity support to teachers. Furthermore not all teachers may need to invest the amount of time required for such high-intensity interventions in 
order to improve their practices (e.g., as demonstrated by Fishman et al., 2013). One major advantage of online courses is that they can be designed to be self-paced so that teachers can access the course at their convenience and for the amount of time they need to learn the information. As discussed above, preliminary research on online courses indicates promise for Internet-based courses to have some effect on teacher practices and/or related constructs (e.g. Fishman et al., 2013; Masters, 2010; Pianta et al., 2008). The topic of classroom management strategies may be particularly well-suited for an online format because it is typically not an entirely new topic for teachers (Briesch, Briesch, \& Chafouleas, 2014; Fabiano et al., 2001). Moreover, online courses can easily be integrated into a district's professional development system so that teachers have yearlong access to resources without having to pay for substitute teachers during training courses or the hassle of scheduling appointments and travel. Online courses may also provide teachers with the choice to engage in professional development topics that are relevant to their current needs. Furthermore, online courses can easily integrate methods of assessment (e.g. content quizzes, satisfaction measures) that may be useful for administrators or for self-evaluation. Providing a variety of training methods that are easily accessible year-round and are flexible to meet teachers' demanding schedules may have far-reaching implications for the effectiveness of professional development. Therefore, in the larger scope of research on the effectiveness of professional development, it will be useful to discover if online workshops have a role in improving classroom management practices and related constructs that are linked to better classroom management practices. 


\section{Theoretical Model of Teacher Change}

Ideally, the outcome to be measured after a skills-based professional development program is the fidelity and quality of the individual's implementation of the strategies taught at the workshop. However, it may also be useful to measure constructs that are thought to be the precursors of behavior change in order to better understand the process of behavior change. Social cognitive theories of behavior change, which are the most researched, have found that variables such as attitudes, self-efficacy, knowledge, and motivation may be related to behavior change (Damschroder et al., 2009). Motivation is defined as the individual's intent to perform a behavior (Ajzen, 1991). When behavior change itself is not directly measured, motivation to change is often examined as it may represent cognitive processes that facilitate implementation and perhaps sustainability (Damschroder et al., 2009; Shoenwald, Hoagwood, Atkins, Evans, \& Ringeisen, 2010; Webb \& Sheeran, 2006). Individual characteristics such as attitudes and self-efficacy have been studied most frequently in relation to behavior change and motivation to change (Damschroder et al., 2009). The current study posits a theoretical model of teacher change in skill implementation presented in Figure 1.

Low-intensity trainings in particular may influence important precursors and predictors of behavior change, even when they do not influence actual behavior change for some individuals. Typically, even the lowest intensity trainings lead to increases in knowledge (e.g., Jones \& Chronis-Tuscano, 2008). Knowledge assessments, usually in the form of a quiz, are a required component from most continuing education accrediting bodies for online courses and are generally recommended to include with professional development training (McHugh \& Barlow, 2010). One problem is that increases in 
knowledge have not shown direct links to increases in skill (Decker, Jameson \& Naugle, 2011; Parrish \& Rubin, 2011). As posited in the theoretical model in Figure 1, perhaps knowledge is not directly linked to behavior change, but influences an individual's motivation to change.

Teacher self-efficacy is one of the most frequently studied constructs and has been identified as an important construct that both predicts classroom management practices and can be changed by professional development programs (Domitrovitch et al., 2008; Han \& Weiss, 2005). Teacher self-efficacy is defined as the teacher's belief in his/her capabilities to bring about desired outcomes in students (Tschannen-Moran \& Hoy, 2001). Teachers' efficacy beliefs are related to student achievement, their interactions with students in the classroom, and their willingness to adopt innovations (Brouwers \& Tomic, 2000; Tschannen-Moran \& Hoy, 2001). Along with self-efficacy, attitudes about the techniques being taught are another individual characteristic related to behavior change and motivation (Damschroder et al., 2009; Domitrovitch et al., 2008). Attitudes as defined as the individual's perception of the effectiveness of the strategies being taught have been shown to relate to both increases in skill and motivation (Domitrovitch et al., 2008). Considering that attitudes and self-efficacy are thought to be precursors of behavior change and may represent cognitive processes that facilitate implementation and sustainability, it is important to understand if training influences these variables.

Studies show that although years of education are not related to better implementation, more familiarity with the strategies presented at trainings leads to better implementation (Han \& Weiss, 2005; Lopez, Osterberg, Jensen-Doss, \& Rae, 2011). 
Downer, Locasale-Crouch, Hamre, and Pianta (2009) examined predictors of uptake for a high-intensity web-based training and they found that past training experience, selfefficacy beliefs, and initial skill level were significantly associated with uptake. Survey studies of teachers in various stages of their careers showed that teachers reported familiarity with many effective behavioral strategies used for managing disruptive students (Briesch, Briesch, \& Chafouleas, 2014; Fabiano et al., 2001). Teachers who indicate greater familiarity with the strategies presented in the training may experience enhanced effects of the training compared to teachers who have not had any past training in the techniques presented. It may be that professional training has an increased positive effect on self-efficacy and effectiveness beliefs when teachers have already had previous training in the same techniques.

Self-efficacy, attitudes, and knowledge may impact the uptake of skills by influencing motivation to implement these skills. However, even people who are highly motivated may not be able to implement skills due to barriers such as limited resources or time. A study that examined the variability in initial implementation following a workshop found that barriers to implementation, motivation to implement, and previous familiarity with skills predicted $45 \%$ of the variance in self-reported implementation (Kuriyan \& Pelham, 2012). Therefore, the relationship between motivation and actual implementation may be influenced by the number of barriers the individual faces.

\section{Current Study}

The current paper presents results from a study examining a randomized evaluation of an online course on classroom behavior management strategies. Participants were elementary school teachers who were randomized either to a waitlist or training 
group. Teachers completed observations and questionnaires during at baseline, posttraining, and follow-up. Observations and questionnaires focused on knowledge, attitudes, barriers, self-efficacy, motivation, and implementation of strategies taught in the course. The first aim of the study pertains to the first part of the theoretical model in Figure 1 and examines whether the training's effect on self-efficacy, knowledge, and attitudes toward the strategies are moderated by past training experiences. I hypothesize that the training will improve all three precursors of behavior change and that teachers who indicate more familiarity with techniques will improve to a greater extent. The second aim of the study addresses the second part of the theoretical model in Figure 1. I hypothesize that self-efficacy, attitudes, and knowledge will predict motivation to implement. The third aim addresses the last part of the theoretical model in Figure 1 and examines whether the predictive relationship between motivation to implement and demonstration of skills is influenced by implementation barriers faced by the teacher. I hypothesize that teachers who have low motivation will have a low level of skill implementation regardless of barriers faced. In addition, I hypothesize that teachers with high motivation will have higher levels of skill implementation compared to those with low motivation, but those who also experience high barriers will demonstrate improvements to a lesser extent compared to those with low barriers. The last aim examines the direct effect of the online professional development program on teacher's implementation of classroom behavior management strategies. I hypothesized that the online course may have an impact on some, but not all, measures of implementation of strategies. 


\section{METHOD}

\section{Participants}

Participants included 57 first through fifth grade special education and regular education teachers. Participants were recruited from the Miami-Dade County Public school district through the district's online professional development system. The portal is the district's Master Plan for In-Service Education for which teachers can earn Master Plan Points toward their professional educator's certificate. With the cooperation of the school district, the online training that is included in the current study was integrated in the Master Plan catalog, which could be viewed by all teachers. Teachers who were interested in the course were able to register online. Once registered, an administrator from the school district provided the list of registrants to the study team, and registrants were then contacted and informed of the study. Teachers who met inclusion criteria and were willing to participate in random assignment were recruited into the study.

First to fifth grade elementary teachers who teach an academic subject and had at least one child in the classroom they considered as disruptive were eligible to participate in the study. Participant demographics are included in Table 1. Teachers were randomized to a waitlist $(\mathrm{N}=28)$ or training group $(\mathrm{N}=29)$. All participants were lead teachers, with three male and 54 female teachers. Participants' educational degrees were as follows: Bachelor's Degree (31.8\%), Education Specialist (13.6\%), Master's Degree $(52.3 \%)$, and Other $(2.3 \%)$. Chi-square or t-tests were utilized to determine whether there were any significant group differences between teachers in the waitlist and training groups and teachers who dropped out of the study versus those who remained as participants. See Figure 2 for a diagram of participant flow. Dropouts did not differ 
compared to those who remained enrolled on any demographic variable. The reasons for dropping out were lack of time $(n=6)$, illness $(n=1)$, and change of teaching assignment $(\mathrm{n}=2)$. Teachers in the waitlist and training groups did not differ on any individual or school-level demographic variable. Teachers represented 31 schools in the Miami Dade County Public School system. On average, schools had a minority student rate of $92 \%$, ranging from $65-100 \%$.

\section{Procedure}

Once enrolled in the study, the first set of baseline observations and a questionnaire packet were scheduled and completed. After the baseline assessment, participants were randomized either to a training group or a waitlist group. After randomization, teachers in the training group received access to the course immediately, while teachers in the waitlist group received another set of observations and a questionnaire packet two weeks after baseline. After teachers in the waitlist group completed the second assessment, they received access to the online course. The waitlist group received a follow-up assessment after completion of the online course. All teachers were asked to try to complete the course within two weeks of receiving access. Course completion took anywhere from 1-113 days with a mean of 27 days and a median of 22 days of active course access.

\section{Measures}

Observations. The Student Behavior Teacher Response system is the observation measure used in the current study (SBTR; Pelham, Greiner, \& Gnagy, 2008). The SBTR collects the frequency of rule violations in the classroom, the teacher's acknowledgement of the rule violation, and the consequence provided. Teacher acknowledgement and 
consequence are coded as appropriate, inappropriate, no response, or not observed. In addition, observers record the number of commands and social reinforcement given by the teacher. Commands are coded as inappropriate and appropriate. Both social reinforcement and commands are categorized as group or individual. A post-observation assessment is also included, during which observers rate the teacher's overall effectiveness on 1) social reinforcement, 2) commands, 3) behavior management strategies, 4) tone of voice, and 5) overall climate set in the classroom. Qualitative ratings are on a scale of 1 (not at all effective/very negative) to 7 (very effective/positive).

Scoring for the frequency variables involved summing each instance of rule violation, dividing by the number of minutes observed, and then multiplying by 60 to create a per-hour rate. A percentage was created for teacher responses to rule violations by summing instances from each response category (inappropriate, appropriate, and no response), dividing by the total rule observed violations, and multiplying by 100 .

The SBTR has been used in other federally funded studies (e.g., Fabiano et al., 2010; Massetti, Pelham, \& Waschbusch, 2007; Waxmonsky et al., 2010) in kindergarten through $6^{\text {th }}$ grade classrooms. In addition, Vujnovic and colleagues (2014) examined the psychometric properties of the SBTR in a pre-school classroom setting and found good interrater reliability for the frequency codes and concurrent, convergent, and discriminant validity of the SBTR qualitative ratings with the Classroom Assessment Scoring System observation system (Pianta et al., 2008).

Observers were advanced undergraduate and graduate students. All observers were required to memorize the operational definitions in the SBTR. Observers completed a 10 hour initial training, which included discussion of the coding system, coding live 
role plays, review of video examples, and coding in practice classrooms of teachers who were not involved in the study. In addition, following winter break, a second training meeting was held to review the coding system with practice coding with video examples before the study resumed in January.

In addition to the SBTR, observers completed an integrity checklist of classroom management techniques (CMT) that were compiled based on the techniques taught in the online workshop. Techniques are rated as $(0=$ none, $1=$ rarely, $2=$ sometimes, $3=$ often). The rating scale is the same one used for the Teacher Behavior Rating Scale observation code (Landry, Crawford, Gunnewig, \& Swank, 2004). A mean score was computed for each observation. In support of the validity of the CMT mean score, the CMT mean score significantly correlated with all of the qualitative measures of effectiveness from the SBTR ( $r$ ranged from .41-.7, $\mathrm{p}<.001$ ).

Each teacher was scheduled to have three 30 minute observations for each assessment point (baseline, post-workshop and follow-up as applicable) on three different days. Reliability observations were completed for $10 \%$ of the observations. Teacher completion for observations at each phase is as follows: Baseline (three observations $=53$ teachers, 2 observations $=4$ teachers $)$; post-workshop $(3$ observations $=50,2$ observations $=3)$, follow-up $(3$ observations $=20,2$ observations $=2)$. To maximize consistency in observational periods, only instructional periods were observed (e.g., rather than test days or special events). Observers were blind to the teacher's randomized condition status and study hypothesis. Inter-rater reliability was supported by nonsignificant paired samples t-tests for all observational variables. In addition, inter-rater agreement on qualitative scores for the SBTR (within 1-point) across the five categories 
ranged from $68 \%$ to $94 \%$ and correlations between the two observers ranged from $.64-.89$ $(p<.05)$. The intraclass correlation coefficient for the classroom management techniques variable was .83 $(p<.001)$, which is in the excellent range (Cicchetti, 1994).

Online Workshop. The online workshop was developed as part of a national initiative to decrease barriers to training in evidence-based practices spearheaded by the Society of Child Clinical and Adolescent Psychology (Division 53 of the American Psychological Association) and in collaboration with Florida International University's Center for Children and Families, and The Children's Trust (www.effectivechildtherapy.fiu.edu). The workshop is led by George DuPaul, Ph.D., the Chair and Professor of School Psychology in the Department of Education and Human Services at Lehigh University. Dr. DuPaul's area of clinical and research expertise is on school-based assessment and interventions for children with attentiondeficit/hyperactivity disorder (ADHD) and related disorders. In the workshop Dr. DuPaul describes the rationale behind and provides examples of a variety of interventions that can be used in the classroom. The following interventions/concepts are covered in the workshop: data-based decision making, classroom rules, repeated assessment, selfmonitoring interventions, self-management, reprimands, and daily report cards, among others.

The workshop was video-taped with a live audience. The online course includes the five-hour workshop video divided into four smaller segments, accompanying downloadable PowerPoint slides and case examples, and a reference list. Within the online course, participants are able to pause, replay, or stop the video as they wish, and may mark each segment when completed. After each video segment is completed, 
participants are prompted to complete a multiple choice quiz derived from the content of the course. The online course allows participants only two chances to complete quizzes. Teachers were required to achieve an average score of $80 \%$ on the quizzes in order to receive their Master Plan Points. At the conclusion of the course, participants are asked to complete a workshop satisfaction survey. The course requires a log-in name and password for each participant. Course data are collected on a secure server.

The principal investigator verified teacher completion and progress in course by checking course access dates, progress and scores of each quiz, and verifying completion with teachers. All teachers (except for partial completers) completed the entire course, all quizzes, and the course evaluation.

Questionnaires. Teachers received a packet of questionnaires at the first observation visit for each assessment point, which they were expected to complete in time to be collected for the third observation visit. See Table 2 for the assessment schedule.

Classroom information and Internet use questionnaire. The Internet use questionnaire consists of relevant items from the survey entitled "Teachers' use of Educational Technology in U.S. Public Schools" administered by the National Center for Education Statistics Survey-Fast Response Survey System. The survey asks about the ease of Internet access and frequency of use of the Internet for professional purposes. This survey also contains questions about basic information about the classroom and teacher, such as number of students in the classroom, educational background of the teacher, and past experiences with professional development. The information from this 
questionnaire was used to provide descriptive information about the teacher and classroom setting.

Checklist of classroom management techniques. The questionnaire was designed by the principal investigator and is adapted from a classroom management techniques survey used in previous studies (e.g., Massetti et al., 2007; Vujnovic, Fabiano, \& Pelham, 2007). There are three versions of this questionnaire: Past Training, Perceived Effectiveness, and Motivation to Implement. On each of the versions, participants were presented with a list of classroom management techniques based on the online course. For the Past Training version, participants were asked to mark the techniques for which they had previous formal coursework and to indicate the techniques that they are most likely to use in their classroom for instructional and general classroom management strategies. Data for the Past Training measure was entered as a binary variable $(0=N o$ coursework or 1 = Prior coursework indicated) and summed, representing the total number of techniques for which they indicated familiarity. For the Perceived Effectiveness version, teachers were asked to rate their perceived effectiveness of each technique on a four point Likert scale $(1=$ Not effective to $4=$ Very effective $)$; a total score was created by computing the average of all items. The Motivation to Implement version is based on a scale designed to assess readiness-to-adopt by McGovern and colleagues (2004). Participants were asked to rate their motivation to implement each technique on a five point Likert scale ( $1=$ I am not interested and do not think this practice would be effective to $5=I$ have been using this practice and efforts are in place to maintain it). A total score was utilized by computing the average of all items. 
Knowledge quiz. Participants completed a 30-item multiple choice quiz that is a standard part of the online workshop (a requirement from licensing bodies to earn online continuing education credits) and reflects the content of the workshop. The Training group completed this quiz during the online workshop. The Waitlist group also completed this quiz for the baseline assessment in order to facilitate group comparisons in knowledge.

Computer based training attitudes scale (CBTAS). The CBTAS is a 13-item scale that demonstrates acceptable reliability ( $\alpha=.68-.88$, Becker \& Jensen-Doss, 2013). Participants responded using a Likert-scale $(1=$ Strongly Disagree to $5=$ Strongly Agree). Two factors have been identified: Comfort in Using and Belief in Efficacy. The information from this questionnaire was used to provide descriptive information.

Teacher sense of efficacy scale (TSES). The TSES short-form is a 12-item questionnaire answered on a Likert-scale $(1=$ Nothing to $9=A$ Great Deal $)$ on teacher's beliefs about how much they can do to impact their classroom policies and students. Three factors have been identified: Student Engagement $(\alpha=.81)$, Instructional Practices ( $\alpha=.86)$, and Classroom Management $(\alpha=.86)$. The total score $(\alpha=.90)$ was utilized in the current study and was computed by taking the mean of all items. Construct validity and reliability has been established for the total score and each of the three subscales (Tschannen-Moran \& Hoy, 2001).

Workshop evaluation. The 17 -item workshop evaluation questionnaire is a standard part of the online course. It asks basic demographic questions (e.g., type of professional setting, educational degree) and questions regarding satisfaction with the workshop. The satisfaction questions were answered on a Likert-scale $(1=$ Strongly 
Disagree to 5 = Strongly Agree). The questionnaire was used to provide descriptive information.

The Texas Christian University (TCU) workshop assessment at follow-up. The TCU consists of two parts, of which only the second part measuring barriers to implementation was used in this study (Bartholomew, Joe, Rowan-Szal, \& Simpson, 2007). The second part of the TCU consists of 8 items, answered on a Likert-scale $(1=$ Strongly Disagree to $5=$ Strongly Agree) regarding the reasons that teachers have not implemented the techniques in the video (e.g. lack of time, school lacks resources, techniques seem cumbersome). The questionnaire was modified to be relevant to teachers (e.g. changing the word from counseling to teaching). Items are scored by averaging responses (after reverse scoring relevant items) and multiplying by 10 to rescale the items.

\section{DATA ANALYSIS}

All analyses included teachers who completed the course along with partial completers. Prior to analysis, data were examined for outliers, normality, homogeneity of variance, homogeneity of regression slopes, and multicollinearity. There were no missing data. All analyses, except for the percentage data, were conducted in a structural equation modeling framework using analysis of covariance (ANCOVA) methods to take into account the pre-test differences. ANCOVA has been shown to be a powerful method of analysis used for randomized trials (Rausch, Maxwell, \& Kelley, 2003). The SBTR teacher response variables (acknowledgement and consequence to rule violations) were analyzed using negative binomial regression with the pre-training variables as covariates in the model. Negative binomial regression was used to account for the non-normality of 
percentage data and overdispersion. Since some teachers in the study were from the same school, the design index was calculated for each analysis in order to estimate the effect of this violation of independence (Lai \& Kwok, 2014). The design effects for all analyses were below 2 and design effect indices lower than 2 have not been shown to overly misrepresent results using single-level analysis (Lai \& Kwok, 2014; Maas \& Hox, 2004).

Although there are no randomized controlled trials of an online workshop on teacher behavior management strategies, there are similar studies that guide our calculation of the required sample size. One study on a three-hour course on behavior management for teachers found large effects for increases in positive behavior strategies $(N=32$; Giallo \& Hayes, 2007). Other studies on online training courses with mental health professionals found large effects on skill acquisition, adherence, attitudes, and self-

efficacy from baseline (Dimeff et al., 2009; Harned, Dimeff, Woodcock, \& Skutch, 2011; Sholomskas et al., 2005). The sample size in each group ranged from 15 to 50 in each condition for these studies. Power analysis was conducted using GPower verson 3.1; in order to determine a large effect, a sample size of 52 is required $(f=.40)$.

\section{RESULTS}

\section{Descriptive Statistics}

Experience with the Internet. All teachers had Internet access at home and at school with $90 \%$ of teachers accessing the Internet from home on a daily basis and $97 \%$ accessing the Internet daily from school. In terms of teacher's use of the Internet, $67 \%$ and $77 \%$ of teachers, respectively, reported using email often to send to individuals and groups. Teachers also reported the frequency of using their own web pages for communication: Never (33.3\%), Rarely (24.6\%), Sometimes (31.6\%), and Often 
$(10.5 \%)$. Lastly, teachers reported the frequency of using instant messaging for communication: Never (38.6\%), Rarely (12.3\%), Sometimes (21.1\%), and Often (28.1\%). Thirty-two percent of teachers reported experience with a computer-based training in the past and on average, teachers reported feeling comfortable $(M=3.86, S D$ $=.72)$ and efficacious with computers $(M=4.24, S D=.61)$ as indicated by positive attitudes on the CBTAS.

Classroom Management Training. Teachers indicated their prior training in a variety of classroom management techniques, which were taught in the workshop, as displayed in Table 3. Teachers were presented with a list of classroom management techniques and were asked to choose the techniques they are most likely to use. The top techniques that teachers stated they were most likely to use were 1) Circulating through the classroom to monitor and provide feedback, 2) Reminding students about expected behaviors, 3) Computer assisted instruction, and 4) Maintaining a brisk pace of instruction. On the basis of CMT observations, the three most frequently utilized techniques at baseline were 1) Maintaining eye contact with students, 2) Maintaining a brisk pace of instruction and 3) Managing transitions appropriately. Self-management and self-monitoring were not observed to be utilized by teachers either at baseline or post-training and time-out was almost never observed.

Information regarding teachers' opinions on their past professional development in classroom behavior management is displayed in Table 4 . The majority of teachers in the current study demonstrated positive attitudes about their past professional development experiences on classroom behavior management. 
Course Satisfaction. Teachers who completed the course also completed the standard evaluation of the course online. Teachers responded to all questions about the course with Strongly Disagree, Disagree, Neither Agree nor Disagree, Agree, or Strongly Agree. The results are presented in Table 5.

\section{Hypothesized Predictors of Behavior Change}

For the first aim, differences between the training and waitlist groups on knowledge were examined. Significant group differences in knowledge, as assessed by the multiple-choice quiz, were evident with a large effect for the training group, scoring on average, 31 points higher than the waitlist group, Waitlist: $M=58.57, S D=10.28$ vs. Training: $M=89.75, S D=5.78 ; F(1,51)=179.07$, partial $\eta^{2}=.78 ; p<.001$.

A multivariate linear model was conducted to examine past training as a potential moderator of the impact of workshop participation on self-efficacy, attitudes, and knowledge. The variable for past-training was centered before creating the interaction term. The interaction effect for past-training and group was not significant for the three outcome variables in the multivariate model, $F(3,45)=2.27 ; p=.09$, partial $\eta^{2}=.13$. Since the interaction was not significant, the interaction was dropped for the subsequent model and only main effects for attitudes and self-efficacy were examined as the main effect for knowledge was reported above (Aiken \& West, 1991). The main effect for group was large and significant for attitudes, with the training group demonstrating a more positive attitude toward classroom management techniques, Waitlist: $M=3.13, S D$ $=.34$ vs. Training: $M=3.4, S D=.35 ; F(1,48)=13.57$, partial $\eta^{2}=.22 ; p=.001$. The main effect was not significant for self-efficacy, Waitlist: $M=7.65, S D=.91$ vs. Training: $M=7.58, S D=1.0 ; F(1,48)=.12$, partial $\eta^{2}=.002 ; p=.73$. 


\section{Predictors of Motivation}

For this set of analyses, post-workshop scores from both the training and waitlist groups were utilized. For the second aim, ANCOVA was used to examine the effects of post-workshop self-efficacy, attitudes, and knowledge on post-workshop motivation to implement, with baseline self-efficacy, attitudes, and motivation as covariates. Attitudes significantly predicted motivation, $F(1,40)=7.84 ; p=.008$, partial $\eta^{2}=.16$ while knowledge, $F(1,40)=.15 ; p=.70$, partial $\eta^{2}=.004$ and self-efficacy, $F(1,40)=.37 ; p=$ .55 , partial $\eta^{2}=.009$ did not.

\section{Skill Implementation}

The third aim was examined using baseline motivation and baseline skill implementation variables as covariates, post-workshop motivation as the predictor variable, and skill implementation as the outcome variable. For this set of analyses, postworkshop scores from both the training and waitlist groups were utilized. An interaction variable was created to examine the moderating effect of barriers on the relationship between motivation and skills implemented. Both the barriers and motivation to implement variables were centered in order to create the interaction term. Measures of skill implementation that were tested as outcome variables include the mean score on the CMT observation and the SBTR effectiveness scores at post-training. The interaction for motivation to implement and barriers was not significant for any outcome variable. The main effect for post-workshop motivation on skill implementation was examined, but did not significantly predict any of the outcome variables. Effect sizes for both the main effect and interaction are reported in Table 6. 
The fourth aim focused on differences between the training and waitlist groups on skill implementation, utilizing variables from the observations. Pre-training scores were used as the covariate and the post-training scores as the outcome variable. Analyses of covariance demonstrated that the training and waitlist groups did not significantly differ in their CMT score, or any of the SBTR outcome variables except for effectiveness of commands. However, when the estimated marginal means of each variable was plotted and examined visually, each variable demonstrated a trend in the hypothesized direction. Means and effect sizes are reported in Table 7. Negative binomial regression models demonstrated that the training and waitlist groups did not significantly differ for any of the SBTR percentage outcome variables. Estimated marginal means and the results from the negative binomial regression are reported in Table 8 .

\section{DISCUSSION}

The current study evaluated the effects of an online classroom management course on teacher behavior, self-efficacy, knowledge, attitudes, and motivation. In addition, information about teacher utilization of the Internet, their opinions about professional development, and experiences with classroom behavior management were described. Elementary school teachers in the study were assigned to a training group or waitlist control group for the online workshop. The first aim of the study examined group differences in the hypothesized predictors of behavior change with teacher's past-training experiences as a moderator. Past-training was not found to be a significant moderator of self-efficacy, knowledge, or attitudes. However, the main effect for training group was significant for attitudes and knowledge but not for self-efficacy. The second aim of the study demonstrated that teacher attitudes but not knowledge and self-efficacy post- 
training significantly predicted motivation to implement. The third aim of the study examined the moderating effect of barriers on motivation to implement and classroom management skill implementation. Barriers were not found to be a significant moderator of motivation and skill implementation. The fourth aim of the study found that for one observational variable, effectiveness of teacher commands, the training group scored significantly better than the waitlist group, while trends for all other observational variables were in the hypothesized directions.

\section{Teacher's Experiences with the Internet}

My findings show that all teachers had access to the Internet at home and at school, and reported using the Internet on a daily basis. The most frequent method of communicating via the Internet was e-mail, while teacher web-pages and instant messaging were utilized, but not as frequently. Teachers also reported feeling comfortable and efficacious with using computers. These findings are not surprising considering that all teachers had a computer in their classroom. It is also increasingly common for teachers to have to enter student grades on a district portal, check their email for important announcements, and utilize online tools provided by the district (Gray, Thomas, \& Lewis, 2010). Furthermore, there are several computer assisted instructional activities that take place in the classroom, such as lessons utilizing a smart-board or individualized academic activities (e.g., Reading Plus online program; Gray et al., 2010). My results lend additional support to findings that the Internet has become a ubiquitous part of teachers' professional activities and correspond with a national survey of technology use conducted by the U.S. Department of Education (Gray et al., 2010). 


\section{Classroom Behavior Management Techniques: Training and Use}

I examined familiarity with classroom management techniques and found that the majority of teachers indicated having some training on all the techniques that were presented in the online workshop. Over half of teachers in the current study reported being trained on 17 out of the 23 strategies listed. My results correspond with other studies that demonstrate that teachers are familiar with the majority of behavioral management strategies in the classroom (Fabiano \& Pelham, 2003; Fabiano et al., 2001). Furthermore, I observed that none of the teachers in my study utilized self-management, self-monitoring, or time-out techniques, which could be due to lack of adequate training on these techniques. In practice, these techniques are generally applied to individual students rather than the whole classroom, which may make them more inconvenient for teachers. Time-out, in particular, has been noted as a strategy that concerns some teachers due to the need for individual supervision of the student, the view of it as a restrictive strategy, and its ineffective use (Turner \& Watson, 1999). Some strategies, such as token reinforcement systems and rules, were present in nearly all classrooms, but were rarely observed to be utilized by teachers. For example, in my study, $67 \%$ of teachers had rules that were posted and easily visible in the classroom. However, reviewing or reminding students of the classroom rules was one of the least observed strategies, even after the training. Additional findings resulting from the direct observations will be discussed in the relevant sections below. My descriptive findings correspond with a recent study that examined general education teacher's use of evidence-based strategies in the classroom and found that although teachers used evidence-based strategies in the classroom, their rates of use are lower than what is recommended (Reddy, Fabiano, Dudek, \& Hsu, 2013). 
It appears to be common for teachers to be aware of and even prepare to utilize certain strategies during the school year, but the actual implementation of the strategies is often lacking (Barbetta, Norona \& Bicard, 2005). Professional development experiences during the school year have the potential to improve the impact of teachers' existing strategies.

The majority of teachers in my study indicated feeling satisfied with their past professional development experiences in classroom management, indicating that it met their needs, was convenient, and applied to their students. All teachers also expressed satisfaction with the online course indicating that it should be offered again. Although many teachers seemed satisfied with their past professional development experiences, it is encouraging that teachers were also satisfied with the online workshop, as it may be an excellent opportunity to connect teachers with a larger variety of professional development opportunities. Utilizing an online format may allow teachers to have access to experts and topics that are not available in their own district. In addition, about a quarter of teachers expressed that their past professional development experiences were not applicable to their students nor was it available at a convenient time or place. Consequently, online courses are a potential solution for ameliorating access issues and may be a way for teachers to individualize their professional development experiences.

\section{Precursors of Behavior Change}

I hypothesized that a teacher's past-training in classroom management strategies influenced the relationship between training group and self-efficacy, attitudes, and knowledge. Teachers in the training group scored 31 points higher on the quiz, demonstrating a significant improvement in knowledge. This finding was to be expected considering that teachers in the training group had to earn a passing grade of at least $80 \%$ 
on the quizzes in order to earn continuing education credit for the course. Although increases in knowledge typically have not been found to lead to changes in skill (Decker et al., 2011; Parrish \& Rubin, 2011), the group difference in quiz scores indicates a reliable impact of the intervention on knowledge of classroom management strategies. These findings indicate that a low-intensity online training could be an effective method for disseminating knowledge, which is often a prerequisite to more intensive methods of training.

A main effect for group was found for attitudes such that teachers in the training group had more positive attitudes about the classroom management techniques presented in the course. An improvement in attitudes may make teachers more open to seeking additional resources in improving their skills in classroom management. There were no group differences in self-efficacy, which may be due to a ceiling effect since teachers in the current study had relatively high rates of self-efficacy as the mean score for both groups was around 7.5 out of 9 . Past-training was not a significant moderator of the three outcome variables. It may be the case that the past training that teachers had received in classroom management strategies was largely ineffective, and therefore did not impact their self-efficacy, knowledge, or attitudes about classroom management.

\section{Motivation and Classroom Management Skill Implementation}

Motivation to implement was examined as a possible precursor to behavior change. First, predictors of motivation to implement were examined. There was a large effect for attitudes on post-training motivation scores, but no effect of knowledge and self-efficacy on motivation. The non-significant effects may be due to a restriction in range for both the knowledge and self-efficacy variables as teachers had to score above 
$80 \%$ on the quiz in order to earn their continuing education points, and all teachers in the current study had high rates of self-efficacy.

The moderating impact of barriers on the relationship between motivation to implement and skill implementation was also examined. Contrary to my hypotheses, the amount of barriers faced did not impact the relationship between motivation to implement and actual skill implementation. In addition, there was no predictive relationship between post-training motivation and skill implementation. It is possible that floor and ceiling effects may have impacted the results of the current study as the mean perceived level of barriers was below average, and teachers in the study reported high levels of motivation. Eighty-percent of the sample scored between 3.5 and 5 on the motivation variable, which has possible range of 1-5. Contributing to the ceiling effect may be that teachers overestimated their motivation, or their intent to implement the strategies. Other studies have found that teacher self-report of implementation is much lower than observer reports of implementation (Bickman et al., 2009; Massetti et al., 2007). Consequently, teachers believe they are doing more than what is observed by an independent rater.

\section{The Effects of an Online Workshop on Teacher Skills}

Group differences between the training and waitlist group on skill implementation were found for only one observational variable (effectiveness of commands), although trends for all the other observational variables were in the hypothesized directions. Observational variables included rule violations in the classroom, the use of classroom management techniques, percentage of rule violations that the teacher observed, percentage of rule violations for which the teacher responded appropriately, percentage of rule violations for which the teacher responded inappropriately, percentage of rule 
violations for which the teacher did not respond, and qualitative scores on teacher effectiveness in the following areas: commands, social reinforcement, behavior management, tone of voice, and overall climate. Teachers who participated in the online workshop were observed to give more effective commands compared to teachers in the waitlist group. Teachers who participated in the online workshop compared to the waitlist group also improved in their effectiveness on all other observational variables, but the results were non-significant. It is possible that changes in the effectiveness of commands were more apparent because commands are a high frequency verbalization in the classroom (Reddy et al., 2013). Teachers may have also found the workshop's information about compliance to be particularly salient given that student compliance in the classroom is considered one of the most adaptive and valued behaviors (Walker \& Sylwester, 1998) and noncompliance to be one of the most prevalent misbehaviors (Westling, 2010). No significant group differences were found on the other classroom observation variables, which may be due to the small sample size.

\section{Overall Theoretical Model}

Returning to the theoretical model presented initially (Figure 1), and my hypotheses, I expected to elucidate the relationship among training, precursors of behavior change, and observed behavior change. My results demonstrate that the course was effective in improving two out of my three hypothesized predictors of behavior change (teacher's knowledge and attitudes), but did not have an effect on self-efficacy. I also hypothesized that the predictors of behavior change would influence motivation and findings showed support for attitudes predicting motivation to implement. The last part of my theoretical model hypothesized that motivation would lead to changes in skill 
implementation. This last part of the model was not supported for any of my skill implementation variables. Additionally, none of the hypothesized moderators, pasttraining and barriers, in the model were significant. Taken together, the theoretical model I proposed was not well supported, although a small sample size and restricted range on some of my constructs may have impacted my ability to detect more complex relationships among variables. Hamre and colleagues (2012) tested a similar theory of change model with a much larger sample for a 14-week teacher training and examined whether teacher characteristics, beliefs, knowledge, or skills in identifying effective interactions influenced the effectiveness of their training program but found little support for their model. For both the study by Hamre and colleagues (2012) and mine, the training lead to changes in the constructs relating to behavior change; however, it was difficult to discern indirect relationships among the training, hypothesized constructs, and skill implementation. Thus, within the teacher training literature, it is still unclear how precursors of behavior change relate to actual behavior change.

\section{Limitations}

The limitations of the current study include its small sample size, which may have led to reduced power to find significant effects of the intervention. In addition, some of the variables (e.g. self-efficacy and motivation) had a restricted range and consequently, only represent a subsample of teachers along those constructs. Self-selection may have also occurred as teachers in the current study chose to participate in a course on classroom management. Therefore, relating to the restricted range in constructs, teachers who were particularly motivated to learn about classroom management may be overrepresented in the current sample. The current study only examined classroom 
behavioral management strategies but not instructional practices. In the future it would be beneficial to examine both in tandem as effective and engaging instructional practices influence student behavior and may be thought of as a form of antecedent behavior management.

\section{Future Directions}

With the current popularity of the response to intervention framework, it is especially important that teachers are able to appropriately implement classroom intervention strategies as students are evaluated in the context of the teacher's interventions. Consequently, it is imperative that school districts provide professional development activities that demonstrate effectiveness in improving teacher utilization of intervention strategies. One of the most consistently effective ways to improve teacher practices is observation coupled with feedback or coaching (Noell et al., 2005; Pianta et al., 2014; Reinke et al., 2014). However, providing effective trainings for teachers can be challenging for school districts as intensive trainings can be expensive and require additional resources. One study estimated that the coaching needs to be approximately 7 to 13 times more effective than more traditional training methods in order to be costeffective (Knight, 2012). Furthermore, even though intensive trainings that include feedback have produced change in teacher skills, these trainings do not routinely lead to maintenance of behavior once feedback is withdrawn (Duncan et al., 2013; Noell et al., 2005). Even when high intensity trainings are provided for extended periods of time to promote maintenance, it may be actually be counterproductive, as some teachers have difficulty staying engaged in high intensity trainings for extended periods (Downer, Kraft-Sayre, \& Pianta, 2009). Therefore, low-intensity trainings such as a brief, online, 
self-administered professional development activity may have a role in a more comprehensive curriculum of professional development, particularly in regard to making professional development more efficient, accessible, and cost-effective.

One way to efficiently utilize resources in a school district may be to streamline professional development so that resources are allocated to the most effective procedures for the desired outcome. For example, in-service trainings and online courses are both effective methods to impart knowledge about a topic. However, the in-service training is somewhat resource intensive in that it requires all teachers to be present at one time in one area and requires an individual facilitator. A more streamlined approach may be to utilize online methods to impart new knowledge or information and reserve the personnel resources within a school district for activities such as observation and feedback for teachers who need the additional support. School districts can use a stepped approach to professional development by beginning with the least intensive and most economical methods of professional development and increase the resources and supports as needed. As online learning becomes more advanced, future studies should examine the impact of including online activities that allow for interactive experiences, directed self-reflection, and discussion. One example is a recent study that examined video-based coaching, which took place in an online format and was successful in improving teachers' classroom interactions (Pianta, et al., 2014). The effectiveness of the Internet-based coaching approach is encouraging as it may make providing individualized feedback more easily accessible, particularly in communities where consultation is not widely available. 
Another method for improving the efficiency of teacher professional development may be to strategically think about appropriate content for low-intensity trainings by targeting teacher behaviors that are most likely to have the biggest impact on student behavior. One way to produce an impact on teacher and student behavior is to target teacher behaviors that are high in frequency. For example, as mentioned previously, commands are a frequent verbalization in the classroom. On the other hand, praise is a verbalization that needs to be increased in most classrooms as teachers are generally not providing the recommended rates of praise (Reddy et al., 2013). An effective approach to increasing praise may be to teach teachers to structure their commands so that rather than repeating commands (e.g. "take out your textbook"), the teacher learns to repeat the command embedded as a praise (e.g. "Nice job Sally, for taking out your textbook first") to the students who follow the command immediately. The praise-command has the same function as a repeated command, which is to remind students to comply, and it may have additional benefits such as elevating the rates of praise in the classroom, and enhancing positive teacher-student relationships. As commands are frequently given in the classroom, changing this one aspect of teacher behavior may have a large impact on the classroom environment. Furthermore, focusing on reducing a behavior such as noncompliance in the classroom may have far-reaching effects given that noncompliance often precedes more serious infractions in the classroom (Walker \& Sylwester, 1998).

The content of teacher preparation programs and professional development activities should also emphasize the link between engaging and effective instruction and successful classroom management as effective instructional practices are closely linked with student behavior (Barbetta et al., 2005; Simonsen, Fairbanks, Briesch, Myers, \& 
Sugai, 2008). Instructional practices are strategies utilized by the teacher to teach in a manner that facilitates student learning (e.g., teaching at a brisk pace and allowing students frequent opportunities to respond; Barbetta et al., 2005). As time for professional development is often limited, the best use of training time would be to focus on teacher behaviors that serve multiple purposes. For example, pacing through the classroom is a recommended strategy that has an instructional purpose and can facilitate both antecedent and consequence based classroom management strategies by allowing the teacher to identify and assist children who are struggling with the task, to increase proximity to students and thereby decrease problem behavior, and to identify and provide reminders to children who are off-task. Consequently, one teacher behavior has potential ramifications for three types of student behavior. Future studies should examine the effect of an online course that focuses on potential high-impact, yet easy to implement strategies. Furthermore, a brief online course that allows teachers to focus on one behavior change at a time may be less intimidating and more palatable to teachers.

\section{Conclusion}

The current study investigated the effects of a low-intensity online workshop on teacher knowledge, attitudes, motivation, and classroom management practices. The online workshop had large effects on knowledge and attitudes and a medium effect on

one index of teacher practice. Although the current study found only limited effects of the brief online workshop, future research may discover ways to utilize an online format jointly with other evidence-based methods to facilitate teacher professional development. Utilized creatively, an online format for professional development may reduce accessibility issues, increase the number of hours that teachers are engaged in 
professional development, and provide a method for individualizing professional development. As the Internet has become a ubiquitous aspect of professional life for most teachers, it is logical to utilize this resource in ways that may enhance professional development. 


\section{REFERENCES}

Ajzen, I. (1991). The theory of planned behavior. Organizational behavior and human decision processes, 50(2), 179-211.

Barbetta, P. M., Norona, K. L., \& Bicard, D. F. (2005). Classroom behavior management: A dozen common mistakes and what to do instead. Preventing School Failure, 49(3), 11-19.

Bartholomew, N. G, Joe, G. W., Rowan-Szal, G. A., \& Simpson, D. D. (2007). Counselor assessments of training and adoption barriers. Journal of Substance Abuse Treatment, 33(2), 193-199.

Becker, E. M., \& Jensen-Doss, A. (2013). Therapist Attitudes Towards Computer-Based Trainings. Administration and Policy in Mental Health and Mental Health Services Research, http://doi: 10.1007/s10488-013-0522-4.

Bickman, L., Riemer, M., Brown, J. L., Jones, S. M., Flay, B. R., Li, K. K., \& Massetti, G. (2009). Approaches to measuring implementation fidelity in school-based program evaluations. Journal of Research in Character Education, 7(2), 75-101.

Briesch, A. M., Briesch, J. M., \& Chafouleas, S. M. (2014). Investigating the usability of classroom management strategies among elementary schoolteachers. Journal of Positive Behavior Interventions, http://doi: 10.1177/1098300714531827.

Brouwers A., \& Tomic, W. (2000). A longitudinal study of teacher burnout and perceived self-efficacy in classroom management. Teaching and Teacher Education, 16, 239-253.

Choy, S.P., Chen, X., \& Bugarin, R. (2006). Teacher Professional Development in 19992000: What Teachers, Principals, and District Staff Report (NCES 2006-305).

U.S. Department of Education. Washington, DC: National Center for Education Statistics.

Cicchetti, D. V. (1994). Guidelines, criteria, and rules of thumb for evaluating normed and standardized assessment instruments in psychology. Psychological Assessment, 6(4), 284.

Cohen, J. (1988). Statistical power analysis for the behavioural sciences (2nd ed.). New York: Academic Press.

Daley, G. \& Kim, L. (2010). A teacher evaluation system that works. National Institute for Excellence in Teaching. Santa Monica, CA. 
Damschroder, L.J., Aron, D.C., Keith, R.E., Kirsh, S.R., Alexander, J.A., \& Lowery, J.C. (2009) Fostering implementation of health services research findings into practice: a consolidated framework for advancing implementation science. Implementation Science, 4 (50).

Decker, S.E., Jameson, M.T., \& Naugle, A.E. (2011). Therapist training in empirically supported treatments: a review of evaluation methods for short- and long-term outcomes. Administration and Policy in Mental Health and Mental Health Services Research. 38 (4), 254-86.

Dede, C., Ketelhut, D. J., Whitehouse, P., Breit, L., \& McCloskey, E. M. (2009). A research agenda for online teacher professional development. Journal of Teacher Education, 60(1), 8-19.

Dimeff, L.A., Koerner, K., Woodcock, E.A., Beadnell, B., Brown, M.Z., Skutch, J.M.,... Harned, M.S. (2009). Which training method works best? A randomized controlled trial comparing three methods of training clinicians in dialectical behavior therapy skills. Behaviour Research and Therapy, 47 (11), 921-930.

Domitrovitch, C.E., Bradshaw, C.P., Poduska, J.M., Hoagwood, K., Buckley, J.A., Olin, S., ,...Ialongo, N.S. (2008). Maximizing the implementation quality of evidencebased preventative interventions in schools: A conceptual framework. Advances in School Mental Health Promotion, 1(3), 6-28.

Downer, J. T., Kraft-Sayre, M. E., \& Pianta, R. C. (2009). Ongoing, web-mediated professional development focused on teacher-child interactions: early childhood educators' usage rates and self-reported satisfaction. Early Education and Development, 20(2), 321-345.

Downer, J. T., Locasale-Crouch, J., Hamre, B., \& Pianta, R. (2009). Teacher characteristics associated with responsiveness and exposure to consultation and online professional development resources. Early Education and Development, 20(3), 431-455.

Duncan, N. G., Dufrene, B. A., Sterling, H. E., \& Tingstrom, D. H. (2013). Promoting teachers' generalization of intervention use through goal setting and performance feedback. Journal of Behavioral Education, 22(4), 325-347.

Emmer, E.T. \& Stough, L.M. (2001). Classroom management: A critical part of educational psychology, with implications for teacher education. Educational Psychologist, 36 (2), 103-112.

Evertson, C. M. \& Smithey, M. W. (2000). Mentoring effects on protégés' classroom practice: An experimental field study. Journal of Educational Research, 93(5), 294-304. 
Fabiano, G.A., \& Pelham, W.E. (2003). Improving the effectiveness of behavioral classroom interventions for Attention-Deficit/Hyperactivity Disorder: A case study. Journal of Emotional and Behavioral Disorders, 11(2), 122-128.

Fabiano, G. A., Pelham,W. E., Pisecco, S., Hannah, J. N., Evans, S., Manos, M. J., \& Caserta, D. (2001, April). Nationally representative survey of treatment for $A D H D$ in the school setting: Preliminary results. Poster session presented at the eighth annual Child Health Psychology Conference, Gainesville, FL.

Fabiano, G. A., Vujnovic, R. K., Pelham, W. E., Waschbusch, D. A., Massetti, G. M., Pariseau, M. E., ... \& Volker, M. (2010). Enhancing the effectiveness of special education programming for children with attention deficit hyperactivity disorder using a daily report card. School Psychology Review, 39(2), 219-239.

Fishman, B., Konstantopoulos, S., Kubitskey, B. W., Vath, R., Park, G., Johnson, H., \& Edelson, D. C. (2013). Comparing the impact of online and face-to-face professional development in the context of curriculum implementation. Journal of Teacher Education, 64(5), 426-438.

Fuchs, D., \& Fuchs, L. S. (2006). Introduction to response to intervention: What, why, and how valid is it? Reading Research Quarterly, 41(1), 93-99.

Giallo, R., \& Hayes, L. (2007). The paradox of teacher professional development programs for behaviour management: Comparing program satisfaction alongside changes in behaviour management practices. Australian Journal of Educational \& Developmental Psychology, 7, 108-119.

Gray, L., Thomas, N., \& Lewis, L. (2010). Teachers' use of educational technology in U.S. public schools: 2009 (NCES 2010-040). National Center for Education Statistics, Institute of Education Sciences, U.S. Department of Education. Washington, DC.

Hamre, B. K., Pianta, R. C., Burchinal, M., Field, S., LoCasale-Crouch, J., Downer, J. T., ... \& Scott-Little, C. (2012). A course on effective teacher-child interactions effects on teacher beliefs, knowledge, and observed practice. American Educational Research Journal, 49(1), 88-123.

Han, S. S. \& Weiss, B. (2005). Sustainability of teacher implementation of school-based mental health programs. Journal of Abnormal Child Psychology, 33 (6), 665-679.

Harned, M.S., Dimeff, L.A.,Woodcock, E.A., \& Skutch, J.M. (2011). Overcoming barriers to disseminating exposure therapies for anxiety disorders: A pilot randomized controlled trial of training methods. Journal of Anxiety Disorders, 25, 155-163. 
Harrison, J.R., Vannest, K., Davis, J., \& Reynolds, C. (2012) Common problem behaviors of children and adolescents in general education classrooms in the United States. Journal of Emotional and Behavioral Disorders, 20(1), 55-64.

Jones, H. A., \& Chronis-Tuscano, A. (2008). Efficacy of teacher in-service training for attention-deficit/hyperactivity disorder. Psychology in the Schools, 45(10), 918929.

Knight, D. S. (2012). Assessing the cost of instructional coaching. Journal of Education Finance, 38(1), 52-80.

Kuriyan, A., \& Pelham, W. (2012, November). Motivation and implementation of skills after a conference on evidence based treatments for youth mental health. Poster presented at the annual meeting of the Association for Behavioral and Cognitive Therapies, Washington DC.

Lai, M. H., \& Kwok, O. M. (2014). Examining the rule of thumb of not using multilevel modeling: the "design effect smaller than two" rule. The Journal of Experimental Education. http://doi: 10.1080/00220973.2014.907229.

Landry, S. H., Crawford, A., Gunnewig, S., \& Swank, P.R. (2004). Teacher Behavior Rating Scale. Unpublished research instrument. Houston, TX: Center for Improving the Readiness of Children for Learning and Education, University of Texas Health Science Center at Houston, 2004.

Lopez, M.A., Osterberg, L.D., Jensen-Doss, A., \& Rae, W.A. (2011). Effects of workshop training for providers under mandated use of an evidence-based practice. Administration and Policy in Mental Health and Mental Health Services Research, 38, 301-312.

Maas, C. J., \& Hox, J. J. (2004). The influence of violations of assumptions on multilevel parameter estimates and their standard errors. Computational Statistics \& Data Analysis, 46(3), 427-440.

Massetti, G.M., Pelham, W.E., \& Waschbusch, D.A. (2007). Teacher fidelity in use of behavior management strategies: Relationships among observations, self-report, and children's disruptive behavior. Poster presented at the annual IES conference, Washington, D.C.

Masters, J., de Kramer, R. M., O'Dwyer, L. M., Dash, S., \& Russell, M. (2010). The effects of online professional development on fourth grade english language arts teachers' knowledge and instructional practices. Journal of Educational Computing Research, 43(3), 355-375. 
McGovern, M.P., Fox, T.S., Xie, H., \& Drake, R.E. (2004). A survey of clinical practices and readiness to adopt evidence-based practices: Dissemination research in an addiction treatment system. Journal of Substance Abuse Treatment, 26 (4), 305312.

McHugh, R.K. \& Barlow, D.H. (2010). The dissemination and implementation of evidence-based psychological treatments. American Psychologist, 65 (2), 73-84.

Means, B., Toyama, Y., Murphy, R., Bakia, M., \& Jones, K. (2010). Evaluation of evidence-based practices in online learning: A meta-analysis and review of online learning studies. Technical Report. U.S. Department of Education, Washington, D.C.

Miles, K. H., Odden, A., Femaanich, M., Archibald, S., \& Gallagher, A. (2004). Inside the black box of school district spending on professional development: Lessons from comparing five urban school districts. Journal of Education Finance, 30, 126.

Nelson, J. R., Maculan, A., Roberts, M. L., \& Ohlund, B. J. (2001). Sources of occupational stress for teachers of students with emotional and behavioral disorders. Journal of Emotional and Behavioral Disorders, 9(2), 123-130.

Noell, G. H., Witt, J. C., Slider, N. J., Connell, J. E., Gatti, S. L., Williams, K. L., ... \& Duhon, G. J. (2005). Treatment implementation following behavioral consultation in schools: A comparison of three follow-up strategies. School Psychology Review. 34(1), 87-106.

Oliver, R. M., \& Reschly, D. J. (2010). Teacher preparation in classroom management: Implications for students with emotional and behavioral disorders. Behavioral Disorders, 35, 188-199.

Oliver, R., Wehby, J., \& Reschly D. J. (2011). Teacher classroom management practices: Effects on disruptive or aggressive student behavior. Campbell Systematic Reviews.

O’Neill, S. \& Stephenson, J. (2012). Does classroom management coursework influence pre-service teachers' perceived preparedness or confidence. Teaching and Teacher Education, 28 (8), 1131-1143.

Parrish, D.E., \& Rubin, A. (2011). An effective model for continuing education training in evidence-based practice. Research on Social Work Practice, 21 (1), 77-87.

Pelham, W.E., Greiner, A.R., \& Gnagy, E.M. (2008). Student Behavior Teacher Response Observation Code Manual. Unpublished Manual. 
Pianta, R. C., DeCoster, J., Cabell, S., Burchinal, M., Hamre, B. K., Downer, J.,... \& Howes, C. (2014). Dose-response relations between preschool teachers' exposure to components of professional development and increases in quality of their interactions with children. Early Childhood Research Quarterly, 29(4), 499-508.

Pianta, R. C., Mashburn, A. J., Downer, J. T., Hamre, B. K., \& Justice, L. (2008). Effects of web-mediated professional development resources on teacher-child interactions in pre-kindergarten classrooms. Early Childhood Research Quarterly, 23(4), 431-451.

Ratcliff, N. J., Jones, C. R., Costner, R. H., Savage-Davis, E., Sheehan, H., \& Hunt, G. H. (2010). Teacher classroom management behaviors and student time-on-task: Implications for teacher education. Action in Teacher Education, 32 (4), 38-51.

Rausch, J. R., Maxwell, S. E., \& Kelley, K. (2003). Analytic methods for questions pertaining to a randomized pretest, posttest, follow-up design. Journal of Clinical Child and Adolescent Psychology, 32, 467-486.

Reddy, L. A., Fabiano, G. A., Dudek, C. M., \& Hsu, L. (2013). Instructional and behavior management practices implemented by elementary general education teachers. Journal of School Psychology, 51(6), 683-700.

Reinke, W. M., Stormont, M., Herman, K. C., \& Newcomer, L. (2014). Using coaching to support teacher implementation of classroom-based interventions. Journal of Behavioral Education, 23(1), 150-167.

Reinke, W. M., Stormont, M., Herman, K. C., Puri, R., \& Goel, N. (2011). Supporting children's mental health in schools: Teacher perceptions of needs, roles, and barriers. School Psychology Quarterly, 26(1), 1-13.

Rice, J. K. (2003). A Framework for Estimating the Cost of Teacher Professional Development. In Wayne K. Hoy, Cecil G. Miskel (Eds.), Studies in leading and organizing schools, (pp. 209-223) Scottsdale, AZ: Information Age Publishing.

Robers, S., Zhang, J., and Truman, J. (2012). Indicators of School Crime and Safety: 2011 (NCES 2012-002/NCJ 236021). National Center for Education Statistics, U.S. Department of Education,

Rose, D. J., \& Church, R. J. (1998). Learning to teach: The acquisition and maintenance of teaching skills. Journal of Behavioral Education, 8(1), 5-35.

Shernoff, E. S., Mehta, T. G., Atkins, M. S., Torf, R., \& Spencer, J. (2011). A qualitative study of the sources and impact of stress among urban teachers. School Mental Health, 3(2), 59-69. 
Sholomskas, D. E., Syracuse-Siewert, G., Rounsaville, B. J., Ball, S. A., Nuro, K. F., \& Carroll, K. M. (2005). I don't train in vain: a dissemination trial of three strategies of training clinicians in cognitive-behavioral therapy. Journal of Consulting and Clinical Psychology, 73(1), 106.

Simonsen, B., Fairbanks, S., Briesch, A., Myers, D., \& Sugai, G. (2008). Evidence-based practices in classroom management: Considerations for research to practice. Education and Treatment of Children, 31(3), 351-380.

Slider, N. J., Noell, G. H., \& Williams, K. L. (2006). Providing practicing teachers classroom management professional development in a brief self-study format. Journal of Behavioral Education, 15(4), 215-228.

Stormont, M., Reinke, W. M., Newcomer, L., Marchese, D., \& Lewis, C. (2014). Coaching teachers' use of social behavior interventions to improve children's outcomes a review of the literature. Journal of Positive Behavior Interventions.

Sutherland, K.S., Lewis-Palmer, T., Stichter, J., \& Morgan, P.L (2008). Examining the influence of teacher behavior and classroom context on the behavioral and academic outcomes for students with emotional or behavioral disorders. The Journal of Special Education, 41 (4), 223-233.

Tschannen-Moran, M., \& Hoy A.W. (2001). Teacher efficacy: Capturing an elusive construct. Teaching and Teacher Education, 17, 783-805.

Turner, H.S., \& Watson, T. S. (1999). Consultant's guide for the use of time-out in the preschool and elementary classroom. Psychology in the Schools, 36(2), 135-148.

Vujnovic, R. K., Fabiano, G. A., Morris, K. L., Norman, K., Hallmark, C., \& Hartley, C. (2014). Examining school psychologists' and teachers' application of approaches within a response to intervention framework. Exceptionality, 22(3), 129-140.

Vujnovic, R., Fabiano, G.A., \& Pelham, W.E. (2007, March). Treatment acceptability for $A D H D$ : The increasing role of teachers. Poster presented at the National Association of School Psychologists conference, New York, NY.

Vujnovic, R.K., Fabiano, G.A., Pelham, W.E., Greiner, A., Waschbusch, D.A., Gera, S., Linke, S. Gormley, M., \& Buck, M. (2014). The Student Behavior Teacher Response (SBTR) system: Preliminary psychometric properties of an observation system to assess teachers' use of effective behavior management strategies. Education and Treatment of Children, 37(2), 323-346.

Walker, H. M., \& Sylwester, R. (1998). Reducing students' refusal and resistance. Teaching Exceptional Children, 30(6), 52-59. 
Waxmonsky, J. G., Waschbusch, D. A., Pelham, W. E., Dragnac-Cordona, L., Rotella, B., \& Ryan, L. (2010). Effects of atomoxetine with and without behavior therapy on the school and home functioning of children with attention-deficit/ hyperactivity disorder. Journal of Clinical Psychiatry, 71 (11), 1535-1551.

Webb, T. L., \& Sheeran, P. (2006). Does changing behavioral intentions engender behavior change? A meta-analysis of the experimental evidence. Psychological bulletin, 132(2), 249.

Wei, R. C., Darling-Hammond, L., Andree, A., Richardson, N., Orphanos, S. (2009). Professional learning in the learning profession: A status report on teacher development in the United States and abroad. Dallas, TX. National Staff Development Council.

Westling, D. L. (2010). Teachers and challenging behavior knowledge, views, and practices. Remedial and Special Education, 31(1), 48-63.

Whitaker, S., Kinzie, M., Kraft-Sayre, M. E., Mashburn, A., \& Pianta, R. C. (2007). Use and evaluation of web-based professional development services across participant levels of support. Early Childhood Education Journal, 34(6), 379-386. 
Figure 1. Proposed theoretical model

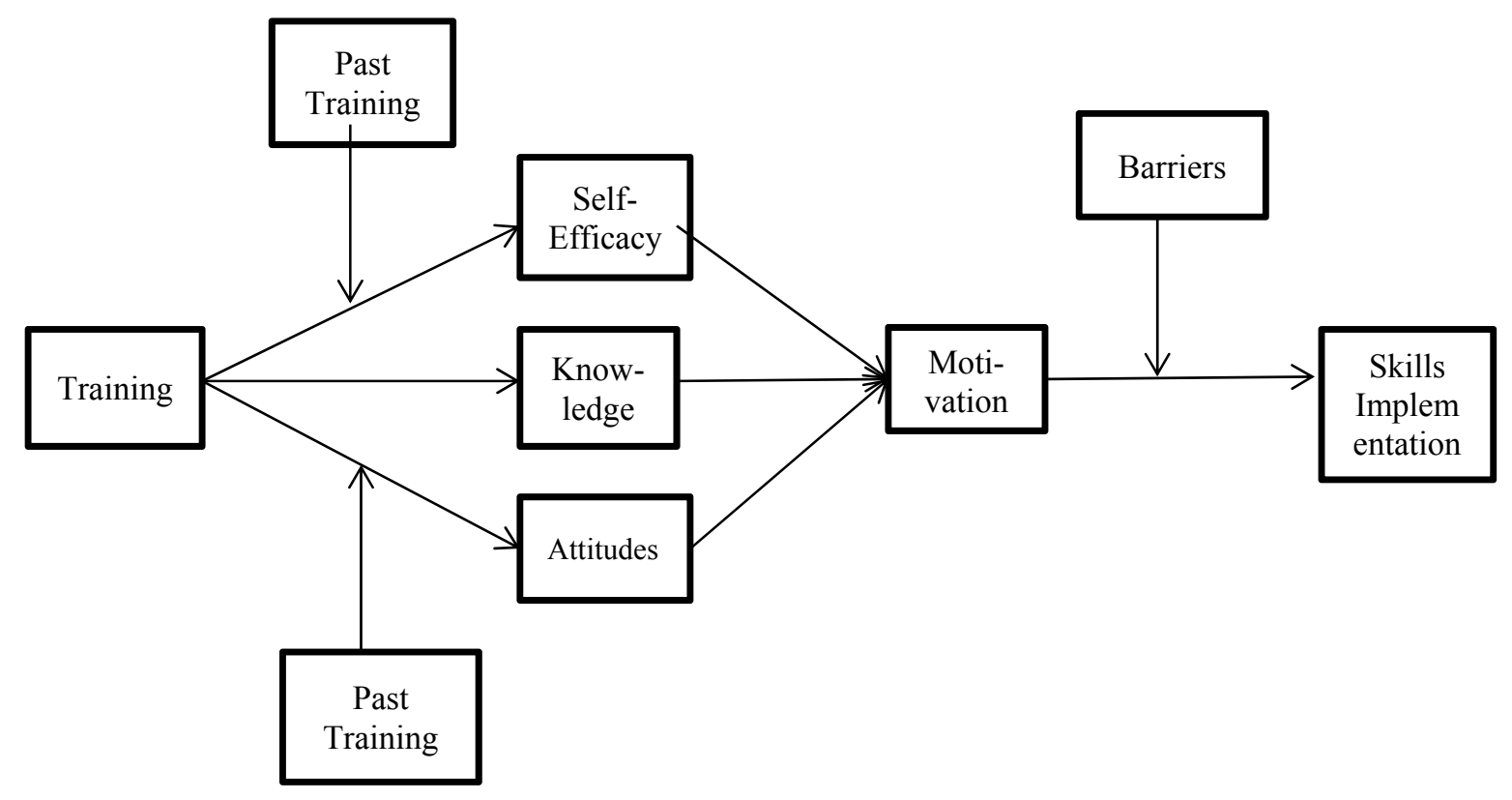


Table 1

Participant Demographics

\begin{tabular}{lll}
\hline & \multicolumn{1}{c}{ Training } & Waitlist \\
& $\mathrm{N}=29$ & $\mathrm{~N}=28$ \\
\hline Number of Students, Mean (SD) & $20.07(7.59)$ & $20(5.74)$ \\
Years of Teaching Experience, Mean (SD) & $13.18(7.84)$ & $14.82(8.34)$ \\
Students with an IEP or 504 Plan, Mean (SD) & $4.82(6.31)$ & $3.86(4.51)$ \\
Prior Professional Development Hours, Mean (SD) & $5.96(13.30)$ & $5.29(1)$ \\
Grades Taught \% (N) & & \\
First & $17.2 \%(5)$ & $28.6 \%(8)$ \\
Second & $24.1 \%(7)$ & $21.4 \%(6)$ \\
Third & $20.7 \%(6)$ & $17.9 \%(5)$ \\
Fourth & $13.8 \%(4)$ & $3.6 \%(1)$ \\
Fifth & $13.8 \%(4)$ & $10.7(3)$ \\
Multiple & $3.4 \%(1)$ & $7.1 \%(2)$ \\
Special Education Classroom & $6.9 \%(2)$ & $10.7 \%(3)$ \\
School Demographics & & \\
Students with Free or Reduced Lunch & $66 \%$ & $62 \%$ \\
School Received an "A" Grade & $66 \%$ & $79 \%$ \\
School Received a "B-F" Grade & $34 \%$ & $21 \%$ \\
\hline
\end{tabular}

Note: The school district assigns a performance grade to each school at the end of each school year based on an algorithm that takes into account student performance on standardized testing. All comparisons were non-significant. 
Figure 2. Participant flow and study design.

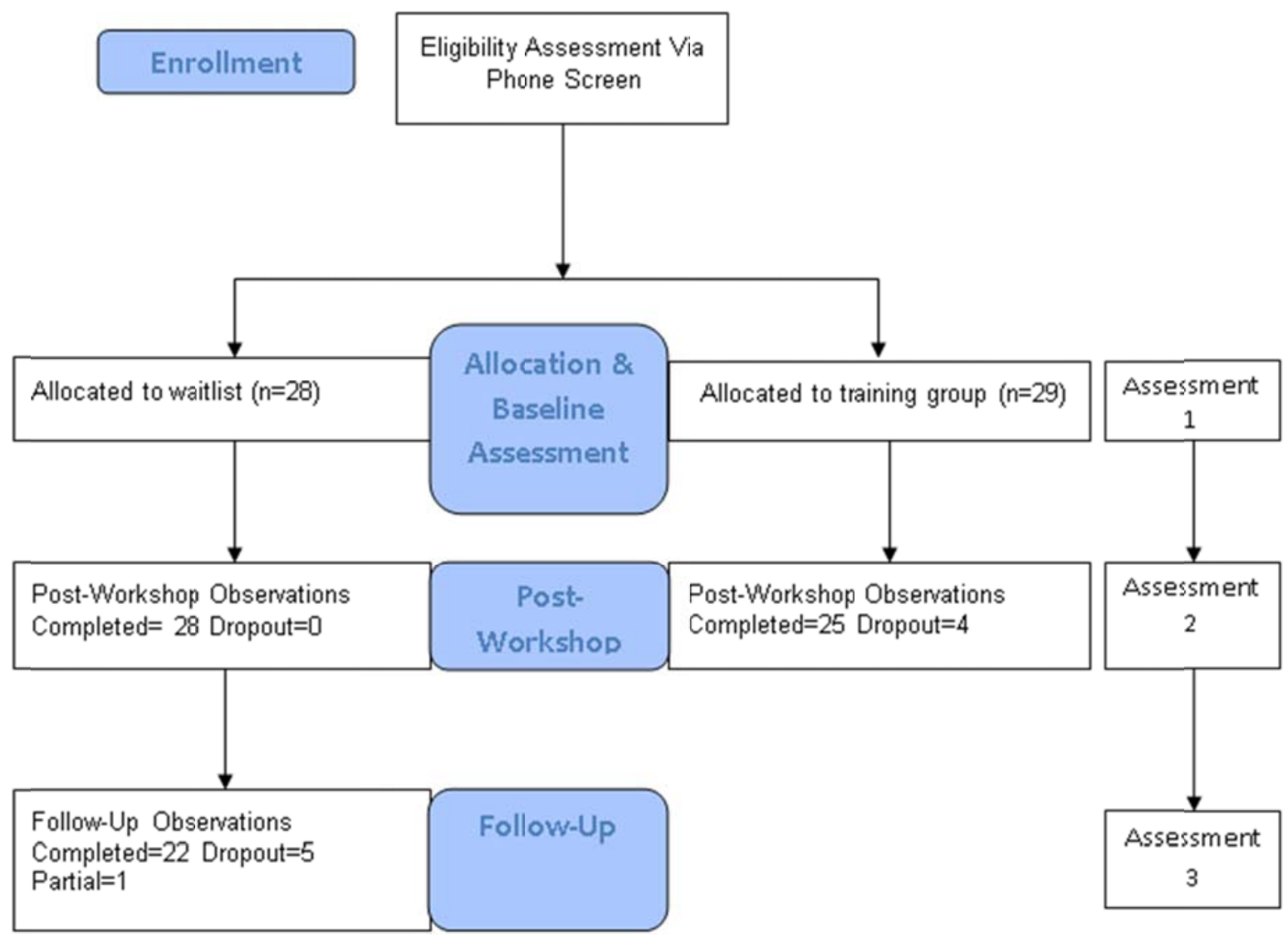


Table 2

Assessment Schedule

\begin{tabular}{|c|c|c|c|}
\hline & Baseline & $\begin{array}{l}\text { Video } \\
\text { Course }\end{array}$ & $\begin{array}{l}\text { Post- } \\
\text { Workshop }\end{array}$ \\
\hline Classroom Information \& Internet Use Ques. & * & & \\
\hline Classroom Observations & * & & $*$ \\
\hline Checklist of Classroom Management & * & & \\
\hline Techniques: Past Training & & & \\
\hline $\begin{array}{l}\text { Checklist of Classroom Management } \\
\text { Techniques: Perceived Effectiveness }\end{array}$ & $*$ & & $*$ \\
\hline $\begin{array}{l}\text { Checklist of Classroom Management } \\
\text { Techniques: Motivation to Implement }\end{array}$ & $*$ & & $*$ \\
\hline Knowledge Quiz & & $*$ & \\
\hline Computer Based Training Attitudes Scale & * & & \\
\hline Teacher's Sense of Efficacy Scale & * & & $*$ \\
\hline Workshop Evaluation & & $*$ & \\
\hline TCU Workshop Assessment at Follow-Up & & & $*$ \\
\hline
\end{tabular}


Table 3

Past Training in Classroom Management Techniques Listed from Most to Least Endorsed

\begin{tabular}{llc}
\hline & $\mathrm{N}$ & $\%$ \\
\hline 1. Circulating through the classroom to monitor and provide feedback & 52 & $91.23 \%$ \\
2. Reminding students about expected behaviors & 50 & $87.72 \%$ \\
3. Using nonverbal cues for redirection & 49 & $85.96 \%$ \\
4. Posting rules in the classroom & 46 & $80.70 \%$ \\
5. Managing transitions & 45 & $78.95 \%$ \\
6. Token reinforcement & 43 & $75.44 \%$ \\
7. Daily or Weekly Home Note & 42 & $73.68 \%$ \\
8. Collecting assessment data & 42 & $73.68 \%$ \\
9. Providing choices to students & 41 & $71.93 \%$ \\
10. Reprimands for inappropriate behavior & 41 & $71.93 \%$ \\
11. Establishing behavioral or academic goals for students & 41 & $71.93 \%$ \\
12. Adjusting the workload for certain students & 39 & $68.42 \%$ \\
13. Use of computer assisted instruction & 39 & $68.42 \%$ \\
14. Periodically reviewing assessment data and revising plan & 37 & $66.07 \%$ \\
15. Maintaining a brisk pace of instruction & 32 & $56.14 \%$ \\
16. Class-wide Peer Tutoring & 31 & $54.39 \%$ \\
17. Response cost procedures & 30 & $52.63 \%$ \\
18. Teaching students self-monitoring & 25 & $44.64 \%$ \\
19. Assignment notebook checking for correct recording of homework. & 24 & $42.86 \%$ \\
20. Time out & 24 & $42.11 \%$ \\
21. Teaching students self-management & 22 & $38.60 \%$ \\
22. Creating an organization checklist with students for notebooks/binders & 19 & $33.93 \%$ \\
23. Providing note-taking training for students & 12 & $21.05 \%$ \\
\hline
\end{tabular}


Table 4

Teacher's Past Professional Development on Classroom Behavior Management

\begin{tabular}{|c|c|c|c|c|}
\hline & Strongly & Somewhat & Somewhat & Strongly \\
\hline & Disagree & Disagree & Agree & Agree \\
\hline & $\%(\mathrm{~N})$ & $\%(N)$ & $\%(N)$ & $\%(\mathrm{~N})$ \\
\hline 1. It met my goals and needs. & $7.8(4)$ & $7.8(4)$ & $70.6(36)$ & $13.7(7)$ \\
\hline 2. It supported the goals and & $7.7(4)$ & $9.6(5)$ & $55.8(29)$ & $26.9(14)$ \\
\hline \multicolumn{5}{|l|}{ standards of my state, district, and } \\
\hline \multicolumn{5}{|l|}{ school. } \\
\hline 3. It applied to the students in my & $5.8(3)$ & $19.2(10)$ & $50(26)$ & $25(13)$ \\
\hline \multicolumn{5}{|l|}{ classroom } \\
\hline 4. It was available at convenient & $9.8(5)$ & $17.6(9)$ & $47.1(24)$ & $25.5(13)$ \\
\hline times and places & & & & \\
\hline
\end{tabular}


Table 5

Results from Course Satisfaction Survey

\begin{tabular}{llllll}
\hline & $\begin{array}{l}\text { Strongly } \\
\text { Disagree }\end{array}$ & $\begin{array}{l}\text { Disagree } \\
\text { Neither } \\
\text { Agree nor } \\
\text { Disagree }\end{array}$ & $\begin{array}{l}\text { Agree } \\
\text { Agree }\end{array}$ & $\begin{array}{l}\text { Strongly } \\
\text { Agree }\end{array}$ \\
\hline $\begin{array}{l}\text { 1. I acquired new knowledge or } \\
\text { skills. }\end{array}$ & $0 \%$ & $0 \%$ & $2.4 \%$ & $40.5 \%$ & $57.1 \%$ \\
$\begin{array}{l}\text { 2. The stated learning objectives } \\
\text { were met. }\end{array}$ & $0 \%$ & $0 \%$ & $0 \%$ & $38.1 \%$ & $61.9 \%$ \\
$\begin{array}{l}\text { 3. Teaching format was suitable } \\
\text { to content }\end{array}$ & $0 \%$ & $0 \%$ & $2.4 \%$ & $56.1 \%$ & $41.5 \%$ \\
$\begin{array}{l}\text { 4. Teaching level was } \\
\text { appropriate }\end{array}$ & $0 \%$ & $0 \%$ & $0 \%$ & $48.8 \%$ & $51.2 \%$ \\
$\begin{array}{l}\text { 5. Handouts were useful. } \\
\text { 6. Presenter was well-prepared. }\end{array}$ & $0 \%$ & $0 \%$ & $0 \%$ & $24.4 \%$ & $75.6 \%$ \\
$\begin{array}{l}\text { 7. Concepts were clearly } \\
\text { explained. }\end{array}$ & $0 \%$ & $0 \%$ & $0 \%$ & $22.5 \%$ & $77.5 \%$ \\
$\begin{array}{l}\text { 8. Presenter was free from bias } \\
\text { or stereotyping. }\end{array}$ & $0 \%$ & $0 \%$ & $0 \%$ & $41 \%$ & $59 \%$ \\
$\begin{array}{l}\text { 9. Presenter was engaging/ } \\
\text { interesting. }\end{array}$ & $0 \%$ & $2.4 \%$ & $2.4 \%$ & $51.2 \%$ & $43.9 \%$ \\
$\begin{array}{l}\text { 10. Course met or exceeded } \\
\text { expectations. }\end{array}$ & $0 \%$ & $0 \%$ & $2.5 \%$ & $67.5 \%$ & $30 \%$ \\
$\begin{array}{l}\text { 11. Course should be offered } \\
\text { again. }\end{array}$ & $0 \%$ & $0 \%$ & $2.5 \%$ & $40 \%$ & $57.5 \%$ \\
\hline
\end{tabular}


Table 6

ANCOVA Examining the Effect of Motivation on Skill Implementation

\begin{tabular}{lccc}
\hline & $\begin{array}{c}F \\
d f(1,40)\end{array}$ & $p$ value & $\begin{array}{c}\text { Effect Size } \\
\left(\text { partial } \eta^{2}\right)\end{array}$ \\
\hline Motivation X Barriers & & .83 & .001 \\
Classroom Management Techniques & .05 & .20 & .04 \\
Commands Effectiveness & 1.69 & .36 & .021 \\
Social Reinforcement Effectiveness & .87 & .07 & .08 \\
Behavioral Management Effectiveness & 3.34 & .65 & .005 \\
Tone of Voice Effectiveness & .21 & .33 & .024 \\
Overall Climate Effectiveness & .97 & .98 & 0 \\
Main Effect of Motivation & & .77 & .002 \\
Classroom Management Techniques & .001 & .66 & .005 \\
Commands Effectiveness & .09 & .85 & .001 \\
Social Reinforcement Effectiveness & .19 & .72 & .003 \\
Behavioral Management Effectiveness & .04 & .45 & .014 \\
Tone of Voice Effectiveness & .13 & .58 & \\
Overall Climate Effectiveness & &
\end{tabular}

Note: $.01=$ small effect, $.06=$ medium effect, $.14=$ large effect (Cohen, 1988) 
Table 7

Group Differences on Observed Skill Implementation

\begin{tabular}{llll}
\hline & Training $M(S D)$ & Waitlist $M(S D)$ & Effect Size \\
& $N=25$ & $N=28$ & (partial $\left.\eta^{2}\right)$ \\
\hline Classroom Management Techniques & $1.12(.23)$ & $1.03(.21)$ & .03 \\
SBTR Rule Violations Per Hour & $71(46.84)$ & $87.61(57.04)$ & .059 \\
SBTR Scores on Effectiveness & & & $.093 *$ \\
Commands & $4.91(1.07)$ & $4.24(.82)$ & .012 \\
Social Reinforcement & $4.05(1.56)$ & $3.69(1.41)$ & .016 \\
Behavioral Management & $3.76(1.45)$ & $3.23(1.14)$ & .001 \\
Tone of Voice & $5.44(1.20)$ & $4.87(1.23)$ & .018 \\
Overall Climate & $5.53(1.19)$ & $5.06(1.28)$ & \\
\hline
\end{tabular}

Note: $01=$ small effect, $.06=$ medium effect, $.14=$ large effect (Cohen, 1988);

Classroom management techniques were rated on a scale of 0 (none) to 3 (very often);

SBTR scores on effectiveness are rated on a scale of 1 (not effective) to 7 (very

effective); ${ }^{*} p<.05$ 
Table 8

Negative Binomial Regression Results for Post-Training Group Differences on Percentage Variables

\begin{tabular}{|c|c|c|c|c|c|c|}
\hline SBTR & Beta & Std. & Odds Ratio & Waitlist & Training & $p$ \\
\hline Percentage & & Error & $(95 \% \mathrm{CI})$ & $\mathrm{N}=28$ & $\mathrm{~N}=25$ & \\
\hline Variables & & & & EMM & EMM & \\
\hline Teacher Observed & -.04 & .28 & $.96(.56-1.65)$ & 69.57 & 72.50 & .89 \\
\hline \multicolumn{7}{|l|}{ Acknowledgement } \\
\hline Appropriate & -.07 & .28 & $.93(.54-1.61)$ & 53.84 & 57.62 & .81 \\
\hline Inappropriate & .27 & .32 & $1.31(.70-2.45)$ & 3.74 & 2.85 & .40 \\
\hline No Response & .06 & .28 & $1.06(.61-1.84)$ & 39.51 & 37.19 & .83 \\
\hline
\end{tabular}

$\underline{\text { Consequence }}$

$\begin{array}{lcccccr}\text { Appropriate } & -.07 & .28 & .93(.54-1.61) & 42.8 & 45.85 & .81 \\ \text { Inappropriate } & .55 & .4 & 1.74(.8-3.81) & 1.68 & .97 & .17 \\ \text { No Response } & .03 & .28 & 1.03(.6-1.77) & 54.06 & 52.64 & .92\end{array}$

Note: Odds ratios indicate the likelihood of the waitlist group differing from the training group post-training. Estimated marginal means (EMM) take into account the effect of the covariate at its mean. SBTR $=$ Student Behavior Teacher Response. Teacher Observed $=$ Percentage of classroom rule violations that the teacher saw. Acknowledgement $=$ Percentage of appropriate, inappropriate, or no acknowledgement of rule violations. Consequence $=$ Percentage of appropriate, inappropriate or no consequence for rule violations. 
VITA

\section{APARAJITA BISWAS KURIYAN}

2001-2005

2005-2007

2007-2008

$2008-2010$

2008-2010

2009

2010-2014

2012-2013
B.A., Psychology and English

University of Rochester

Rochester, NY

Project Coordinator, Judge Baker Children's Center Boston, MA

Research Assistant, Center for Children and Families Buffalo, NY

Graduate Student, Clinical Psychology

University at Buffalo

Buffalo, NY

Presidential Fellowship, University at Buffalo, SUNY

Travel Award, University at Buffalo, SUNY

Doctoral Candidate

Florida International University

Miami, FL

Elizabeth Munsterberg Koppitz Research Runner-up

Fellowship, American Psychological Foundation

\section{SELECTED PUBLICATIONS AND PRESENTATIONS}

Hart, K.C., Kent, K.M., Graziano, P., Biswas, A., and Pelham, W.E. (2011). Promoting successful transitions to kindergarten: An innovative adaptation of the children's summer treatment program for behaviorally at-risk children from Head Start. In K. Hart and W. Pelham (Co-Chairs), Bringing evidence-based behavioral interventions to Head Start: Lessons learned In developing, implementing, and evaluating evidence-based behavioral practices in a national early childhood setting. Symposium presented at the Association for Behavioral and Cognitive Therapies Annual Meeting, Toronto, Ontario, Canada.

Robb, J.A., Sibley, M.H., Pelham, W.E., Foster, E.M., Molina, B.S.G., Gnagy, E.M. \& Kuriyan, A.B. (2011). The estimated annual cost of ADHD to the US education system. School Mental Health, 3 (3), 169-177. 
Sibley, M.H., Pelham, W.E., Mazur, A., Gnagy, E.M, Ross, J.M., Kuriyan, A.B. (2011). The effect of video feedback on social behavior of an adolescent with ADHD. Journal of Attention Disorders. 16(7):579-88.

Pelham, W.E. \& Kuriyan, A.B. (2012, August). Disseminating EBPs for child and adolescent mental health: A web-based initiative. Symposium presented at the annual meeting of the American Psychological Association, Orlando, FL.

Kuriyan, A., \& Pelham, W. (2012, November). Motivation and implementation of skills after a conference on evidence based treatments for youth mental health. Poster presented at the annual meeting of the Association for Behavioral and Cognitive Therapies, Washington DC.

Kuriyan, A. B., Pelham, W., Molina, B., Gnagy, E. M., Waschbusch, D.A., Sibley, M.H., ... Kent, K. (2013).Young adult educational and vocational outcomes of children diagnosed with ADHD. Journal of Abnormal Child Psychology, 41 (1), 27-41.

Kuriyan, A. B., Pelham, W., Molina, B., Waschbusch, D.A., Sibley, M.H, Gnagy, E. M., (2014) Concordance between parent and physician medication histories for children with ADHD. Journal of Child and Adolescent Psychopharmacology. 24(5), 269-274.

Pelham, W.E. \& Kuriyan, A.B. (2012, August). Disseminating EBPs for child and adolescent mental health: A web-based initiative. Symposium presented at the annual meeting of the American Psychological Association, Orlando, FL.

Sibley, M.H., Pelham, W.E., Molina, B.S.G., Gnagy, E.M., Waschbusch, D.A., Garefino, A., Kuriyan, A.B., Babinski, D.E., \& Karch, K.M. (2012). Diagnosing ADHD in adolescence. Journal of Consulting and Clinical Psychology, 80 (1) 139-150.

Sibley, M.H., Kuriyan, A.B., Evans S.W., Waxmonsky, J.G., \& Smith, B.H. (2014). Pharmacological and psychosocial treatments for adolescents with adhd: an updated systematic review of the literature. Clinical Psychology Review, 34, 218-232. 